Federal Reserve Bank of Minneapolis

Research Department Staff Report 423

April 2009

\title{
Inflation and the Price of Real Assets*
}

\author{
Monika Piazzesi \\ Stanford University \\ and National Bureau of Economic Research \\ Martin Schneider \\ Stanford University \\ and National Bureau of Economic Research
}

\begin{abstract}
In the 1970s, U.S. asset markets witnessed $(i)$ a $25 \%$ dip in the ratio of aggregate household wealth relative to GDP and ( $i i)$ negative comovement of house and stock prices that drove a $20 \%$ portfolio shift out of equity into real estate. This study uses an overlapping generations model with uninsurable nominal risk to quantify the role of structural change in these events. We attribute the dip in wealth to the entry of baby boomers into asset markets, and to the erosion of bond portfolios by surprise inflation, both of which lowered the overall propensity to save. We also show that the Great Inflation led to a portfolio shift by making housing more attractive than equity. Apart from tax effects, a new channel is that disagreement about inflation across age groups drives up collateral prices when credit is nominal.
\end{abstract}

*Piazzesi: Department of Economics, Stanford University, 579 Serra Mall, Stanford, CA 94024. Email: piazzesi@stanford.edu. Schneider: Department of Economics, Stanford University, 579 Serra Mall, Stanford, CA 94024. Email: schneidr@stanford.edu. For comments and suggestions, we thank Joao Cocco, Jesus Fernandez-Villaverde, John Heaton, Susan Hume McIntosh, Larry Jones, Patrick Kehoe, Per Krusell, Ricardo Lagos, Ellen McGrattan, Toby Moskowitz, Neng Wang, seminar participants at Boston University, Columbia University, FRB Minneapolis, Indiana University, UCLA, University of Chicago, University of Illinois, University of Michigan as well as conference participants at the Federal Reserve Banks of Atlanta, Chicago, and Cleveland, the Deutsche Bundesbank/Humboldt University, the Bank of Portugal Monetary Economics Conference, and the NBER Real Estate and Monetary Economics Group. The views expressed herein are those of the authors and not necessarily those of the Federal Reserve Bank of Minneapolis or the Federal Reserve System. 


\section{Introduction}

The 1970s brought dramatic changes in the size and composition of US household sector wealth. Figure 1 shows that aggregate household net worth as a fraction of GDP fell by $25 \%$ during the 1970s, before recovering again to its late 1960s value. Figure 2 shows that the aggregate household portfolio saw a $20 \%$ shift away from equity and into real estate during the 1970s. This portfolio adjustment was largely driven by negative comovement of asset prices - house prices rose while equity prices fell, as shown in Figure 3. Compared to the big swings in the major real asset positions, households' net position in nominal credit instruments was relatively stable. As documented below, the stability of net positions masks substantial increases in gross borrowing and lending within the household sector.

This paper develops an asset pricing model with heterogeneous agents and incomplete markets to study the 1970s. The key elements of the model are that households differ by age and wealth and that all credit is nominal, so that inflation matters for bond returns and the cost of borrowing. Our empirical strategy is based on the idea that micro data on household characteristics can be used to directly parametrize household sector asset demand. In particular, the first step of our analysis is to estimate, for each trading period, $(i)$ the distribution of income and initial asset endowments across households and ( $i i$ ) household expectations about future prices and income. We then determine optimal household policies given endowments and expectations. Equilibrium prices equate household asset demand to the supply of assets provided by other sectors. We use this framework to evaluate different candidate explanations for the price and portfolio movements in Figures 1-3.

Our analysis attributes the dip in household wealth to two events unique to the 1970 s that reduced the propensity to save in the household sector. First, entry of the young baby boomers into asset markets directly lowered the average savings rate. Second, the erosion of bond portfolios by surprise inflation reduced the ratio of financial wealth to human wealth, which also gives rise to lower savings. Since there was only a small reduction in asset supply in the 1970s, the lower average savings rate reduced the value of outstanding assets. We also show that the Great Inflation induced a portfolio shift towards real estate. One effect is that various nominal rigidities in the tax code make housing more attractive when expected inflation is high. Another effect we stress is that heterogenous 


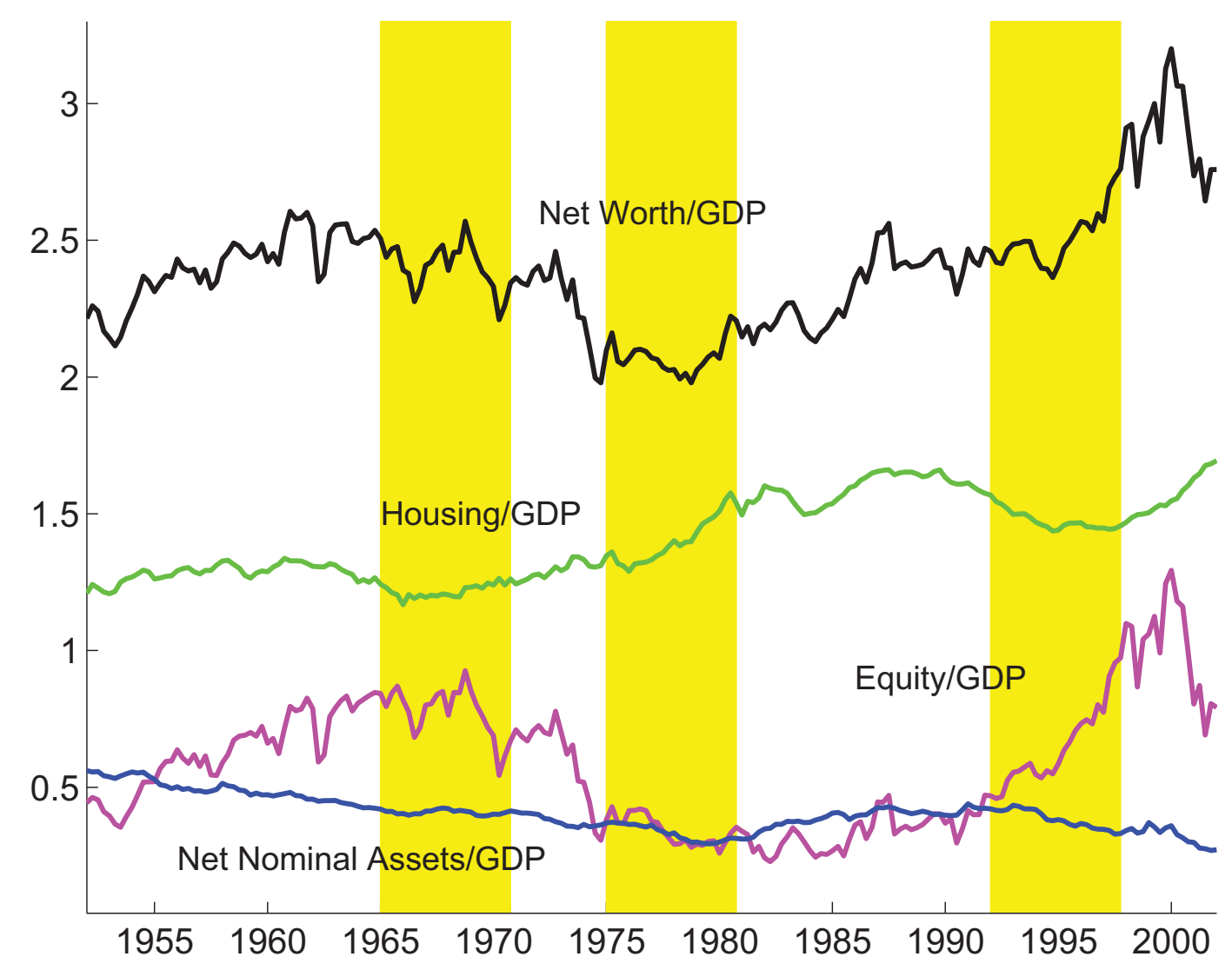

Figure 1: Aggregate wealth components (market value) divided by GDP, Flow of Funds \& own computations, 1952:1-2003:4.

inflation expectations in a nominal credit market increase the volume of credit and drive up the price of collateral.

Our model describes a sequence of trading periods. Households of different ages enter the period with different initial endowments. They trade goods, as well as three risky assets: equity, real estate and nominal bonds. In the credit market, households face collateral constraints - all borrowing must be backed by real estate - as well as a spread between borrowing and lending rates. Moreover, lending and borrowing is required to be in nominal terms - there is no riskfree asset. Households experience idiosyncratic shocks to labor income as well as to the value of their real estate holdings. Neither idiosyncratic risk nor inflation risk are insurable given the available assets.

We implement the model for three 6-year trading periods, highlighted in yellow in Figures 1-3. For each period, we derive household sector asset demand by solving households' consumption-savings problems, given endowments of assets and non-asset income as well as expectations about asset 


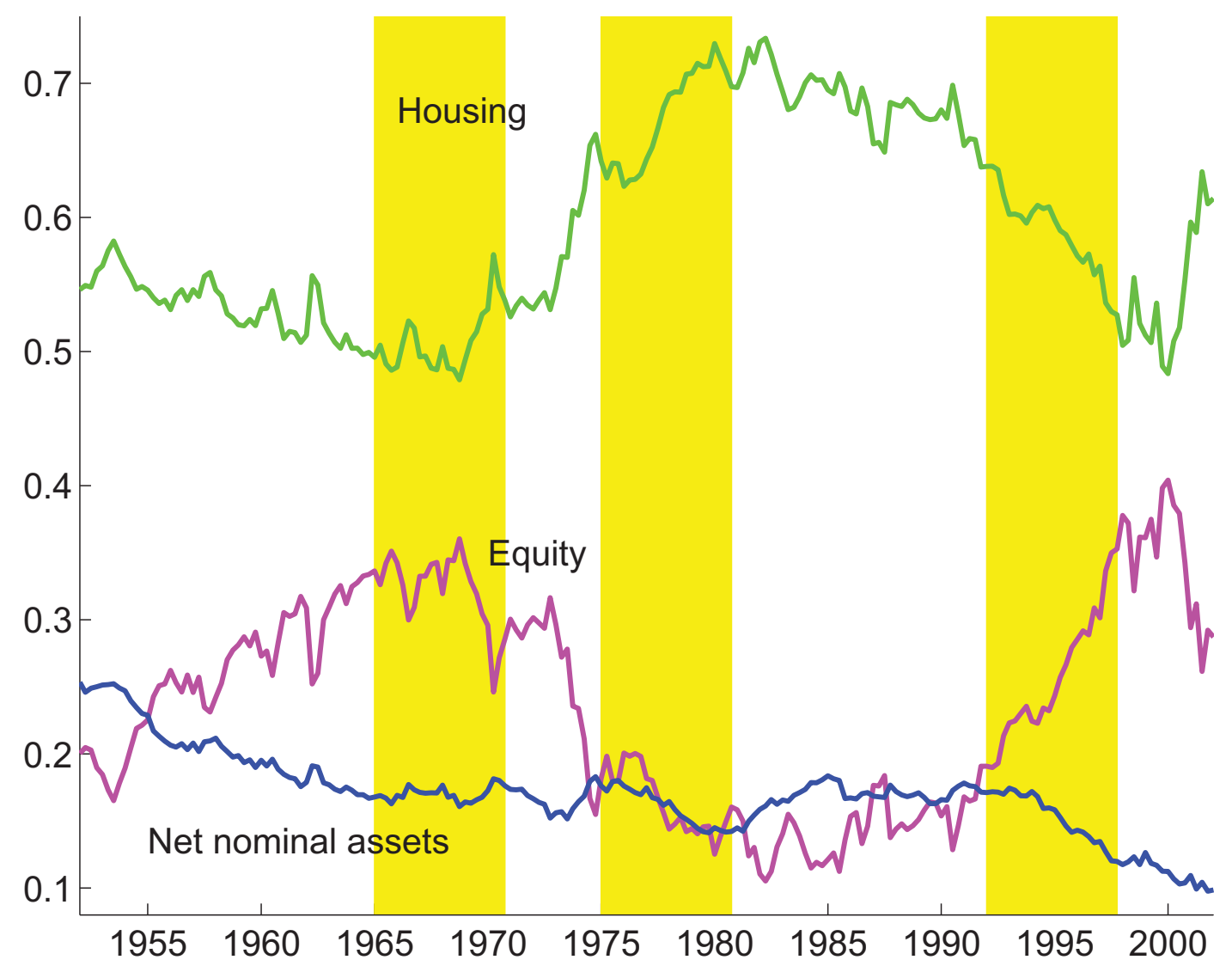

Figure 2: Aggregate portfolio shares, Flow of Funds \& own computations, 1952:1-2003:4.

returns and income in future periods. We then determine asset prices in the trading period by setting aggregate household demand equal to asset supply, where the latter is defined as observed aggregate household asset holdings. Prices thus clear markets to establish a "temporary equilibrium," as in Grandmont $(1977,1982)$. The idea is to view Figures 1-3 as a sequence of temporary equilibria, of which three are explicitly computed.

Our focus on asset demand and supply in a particular trading period leads us to select the exogenous "inputs" to our model differently from existing studies of asset pricing. First, we obtain estimates of the joint distribution of households' income and asset endowments - a key determinant of household asset demand - directly from the Survey of Consumer Finances. These household characteristics are important for the ratio of financial to human wealth and hence for individual savings rates and risk attitudes. The use of micro data on wealth also provides a new perspective on the effect of heterogeneity on asset prices. Existing studies have shown that heterogeneity does 


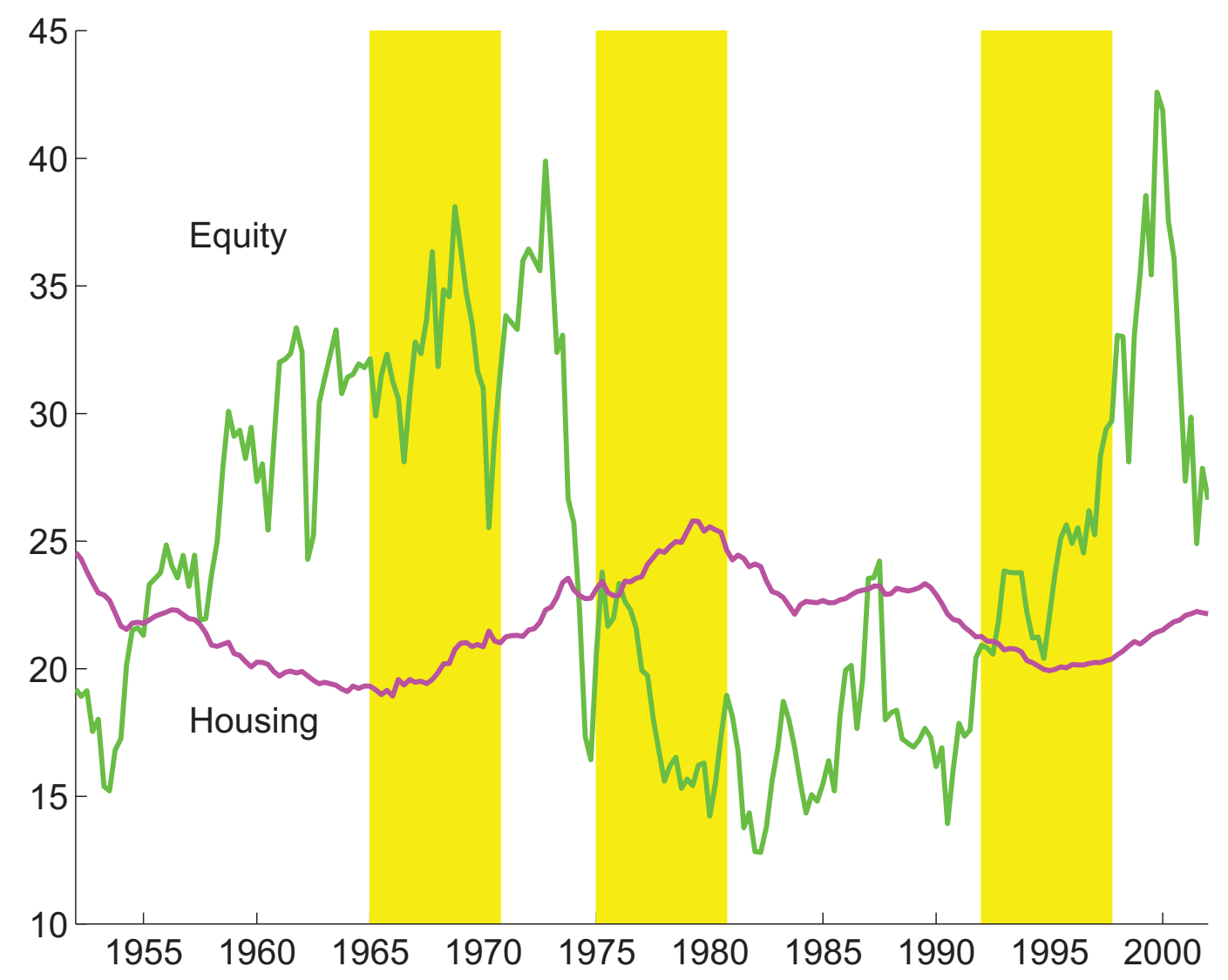

Figure 3: Price-dividend ratio and price-rent ratio, Flow of Funds \& own computations, 1952:12003:4.

not matter if asset demand functions are approximately linear over the support of a model-implied wealth distribution. We examine asset demand in the support of the observed wealth distribution and find that while approximate aggregation obtains within all but the youngest age cohorts, the distribution of wealth across cohorts does matter.

Second, our approach takes expectations of future prices as an exogenous input. Much of our analysis is conducted using a baseline set of beliefs derived from historical data. While we do not force beliefs about future prices to be consistent with the predictions of our model, we do thus impose consistency with observed price data. Treating expectations as an input is also convenient for studying their role during the surprising surge of inflation in the 1970s. To capture households' reaction at the time, we obtain estimates of their forecasts from inflation surveys. We assess the impact of other dimensions of expectation formation through controlled experiments. In particular, we consider increases in subjective uncertainty about inflation and a revision in stock return forecasts 
based on measures of expected inflation, motivated by forecasting regressions popularized in the late 1970s.

Although our model is an endowment economy, we allow for differences between personal income and consumption, and hence changes in the quantities of assets owned by the household sector. We identify changes in asset quantities from changes in household positions recorded in the Flow of Funds Accounts. While we do not model explicitly the decisions of other sectors - such as the government, businesses and the rest of the world - that give rise to the observed asset supply, our approach requires that a successful model be consistent with observed savings decisions by households and observed trades between sectors. In our model, changes in asset supply affect the sensitivity of the equilibrium price response to changes in household demand. For example, a reduction in government debt and an increase in residential investment mitigated the drop in the value of aggregate wealth and the increase in real estate prices in the 1970s.

We select the discount factor and baseline beliefs so that the model replicates the aggregate wealth-to-GDP ratio, household sector portfolio weights, as well as the nominal interest rate in 1995. The baseline model then also matches price dividend ratios of equity and real estate. Moreover, it captures a number of stylized facts about the cross-section of households in the 1995 SCF. In particular, it generates hump-shaped cohort market shares in wealth, real estate and equity, as well as net nominal positions that increase - and real estate shares that decrease - with age and net worth. The main mechanism behind these facts is that agents who expect more future non-asset income are willing to build more risky portfolios.

To illustrate the sensitivity of asset prices to changes in expectations and asset supply, we perform a series of counterfactuals based on the 1995 calibration. The main result here is that events relevant to the stock market spill over much less into other asset markets than events relevant to the housing market, although stock prices are themselves more responsive to changes in expectations. For example, a one percent increase in real stock return expectations over the next six years raises the price dividend ratio of stocks by $15 \%$, but raises the nominal interest rate by only 10 basis points; it lowers the price-dividend ratio on housing by $3.5 \%$. In contrast, a one percent increase in the expected return on real estate raises the house price by $7 \%$, increases the nominal interest rate by 80 basis points, and also lowers stock prices by $13 \%$. The reason for these results is that households 
can borrow against real estate, so that events in the housing market feed back more strongly to the credit market than news about stocks.

We then use the model to examine the 1970s. We show that the model produces a drop in aggregate wealth between 1968 and 1978 for a wide range of expectations scenarios. It attributes the dip in the wealth-GDP ratio to two effects. First, the entry of baby boomers into asset markets lowered the average saving rate. Second, capital losses from realized inflation lowered wealth and hence savings, especially for older households. At the same time, lower savings were not counteracted by a large increase in interest rates, because the outside supply of bonds to the household sector also fell. If we assume that the spread between borrowing and lending rate was 75 basis points higher in 1968 than in 1995, the model also generates the increase in gross borrowing and lending between these two years.

We explore three different channels through which inflation expectations can induce negative comovement of stock and house prices. First, households disagreed about inflation in the late 1970s. We use the Michigan Survey of Consumers to document that old households expected lower inflation than young households. When credit is nominal, disagreement about inflation implies disagreement about real interest rates. As a result, there is more borrowing and lending among households and an increase in the price of collateral, namely housing. Second, nominal rigidities in the taxes code favor housing over equity in times of high expected inflation. Third, expected inflation is a predictor of low stock returns (for example, because inflation lowers depreciation allowances based on historical cost accounting and hence real cash flows), as shown by a number of studies that appeared in the 1970s, such as Fama and Schwert (1977).

Our quantitative analysis suggests that both inflation and growth expectations were relevant for asset prices and household positions in the 1970s, while neither can account for the data by itself. Our model attributes the portfolio shift to changes in inflation expectations. A little more than half of the shift is due to lower stock returns predicted by higher expected inflation, while about one quarter each is due to disagreement about real interest rates and nominal rigidities in the tax code. Disagreement also accounts for the increase in credit volume, which is however mitigated by an increase in inflation uncertainty. Pessimism about growth, which affects both labor income and dividends, increases the demand for savings and partly offsets the effects of pessimism about stock 
returns on the wealth-GDP ratio. At the same time, pessimism about asset returns puts downward pressure on interest rates, thus partly offsetting the effects of expected inflation.

The rest of the paper is organized as follows. Section II discusses related literature. Section III presents the model. Section IV describes the quantitative implementation and documents properties of the model inputs, that is, the joint distribution of asset endowments and income as well as asset supply. Section V derives predictions for optimal household behavior and compares them to the data. Section VI illustrates price determination in temporary equilibrium using counterfactuals. Section VII derives predictions under baseline expectations and shows that they help understand the evolution of the wealth-GDP ratio. Section VIII considers the effect of inflation on portfolio composition in the 1970s. Section IX concludes.

\section{Related Literature}

Some of the effects of inflation that arise in our model have been discussed before. Feldstein (1980), Summers (1981) and Poterba (1991) have examined various ways in which the interaction of taxes and inflation can affect asset prices. One argument is that inflation lowers after tax returns on bonds and stocks more than those on real estate and hence might be responsible for the portfolio shift of the 1970s. We show that this effect contributes to the portfolio shift, although it cannot quantitatively generate all of it. These authors have also argued that inflation has effects on real cash flows because of depreciation allowances. These effects are captured in our pessimism experiments.

Previous literature has shown that demographics cannot account fully for changes in stock prices, if equity is the only long-lived asset in the model (Abel 2003, Geanakoplos et al. 2004). The effect of demographics on house prices in isolation has been considered by Mankiw and Weil (1989) and Ortalo-Magne and Rady (2006). In our model, with both equity and real estate present in nonzero net supply, demographics impact aggregate savings and hence the wealth-GDP ratio, but it can also not account for the larger movements in the individual components of wealth, especially stocks.

There is a large literature on asset pricing models with heterogeneous agents and incomplete markets and/or borrowing constraints. For example, Constantinides and Duffie (1996), Heaton and Lucas (1996), Krusell and Smith (1998), Constantinides et al. (2002) and Storesletten et al. (2004) 
consider models with equity, riskless bonds and uninsurable income risk. Alvarez and Jermann (2001) and Lustig and van Nieuwerburgh (2005) consider models with complete markets, where income risk cannot be insured because of borrowing constraints or collateral constraints backed by real estate, respectively. The goal of these papers is to derive a stationary equilibrium of the model that matches empirical moments of returns such as the equity premium. The input to the model is typically a jointly stationary process for income and dividends, while the output compared to the data are moments of returns and macro aggregates, and sometimes also the cross section of consumption (Brav et al. 2002, Kocherlakota and Pistaferri 2005).

Our paper differs from these studies because of our focus on nominal risk, observed household asset positions, and structural change. Our empirical implementation uses the cross section of household asset positions both as an input to the model and as a target of the analysis. To accommodate structural change, we do not derive a stationary equilibrium that is compared to empirical moments, but consider instead asset prices and holdings at specific dates. In this respect, our approach is similar to that of Barsky (1989) who considers the effect of lower and more volatile economic growth, McGrattan and Prescott (2005) who look at the effect of taxes on stock prices, Nakajima (2005) who considers the effect of precautionary savings on house prices and Campbell and Hercowitz (2005) who study the effect of credit market deregulation on debt levels. However, existing studies that focus on low frequency movements in the economy typically compare steady states or stationary equilibria at different parameter values, while we use the temporary equilibrium concept of Grandmont (1977, 1982).

Portfolio choice with housing has been considered by Flavin and Yamashita (2002), Campbell and Cocco (2003), and Fernandez-Villaverde and Krueger (2005). Cocco (2005) and Yao and Zhang (2005) study intertemporal problems with three assets that are similar to the problem solved by our households. General equilibrium OLG models with housing have been considered by Chambers et al. (2006) and Yang (2006). These papers are also interested in the cross section of house ownership. While they consider a shorter period length and thus study the cross section in more detail than we do, they abstract from aggregate risk which is important for our application. 


\section{Model}

The model describes the household sector's planning and asset trading in a single time period $t$.

\section{A. Households}

Households enter the period with assets and debt accumulated earlier. During the period, they earn labor income, pay taxes, consume and buy assets. Labor income is affected by idiosyncratic income shocks. Households can invest in three types of assets: long-lived equity and real estate as well as short lived nominal bonds. Households face two types of aggregate risk. They face aggregate growth risk through stock dividends and aggregate components of their housing dividends and labor income. They also face aggregate inflation risk when borrowing or lending because there is no riskfree asset. Households also face idiosyncratic risk which affects the return on individual houses and labor income streams. There are only three assets, so markets are incomplete.

\section{Planning Horizon}

Consumers alive at time $t$ differ by endowment of assets and numeraire good as well as by age. Differences in age are represented by age-specific planning horizons $T$ and age-specific survival probabilities for the next period. We now describe the problem of a typical consumer with a planning horizon $T>0$.

Preferences

Consumers care about two goods, housing services and other (non-housing) consumption which serves as the numeraire. A consumption bundle of $s_{t}$ units of housing services and $c_{t}$ units of numeraire yields utility

$$
C_{t}=c_{t}^{\delta} s_{t}^{1-\delta}
$$

Preferences over (random) streams of consumption bundles $\left\{C_{t}\right\}$ are represented by the recursive 
utility specification of Epstein and Zin (1989). Utility at time $t$ is defined as

$$
U_{t}=\left(C_{t}^{1-1 / \sigma}+\beta E_{t}\left[U_{t+1}^{1-\gamma}\right]^{\frac{1-1 / \sigma}{1-\gamma}}\right)^{\frac{1}{1-1 / \sigma}}
$$

where $U_{t+T}=C_{t+T}$. Here $\sigma$ determines the intertemporal elasticity of substitution for deterministic consumption paths, $\gamma$ is the coefficient of relative risk aversion towards timeless gambles, and $\beta$ is the discount factor. The expectation operator takes into account that the agent will reach the next period only with an age-specific survival probability.

Equity

Shares of equity can be thought of as trees that yield some quantity of numeraire good as dividend. A consumer enters period $t$ with an endowment of $\bar{\theta}_{t}^{e} \geq 0$ units of trees. Trees trade in the equity market at the ex-dividend price $p_{t}^{e}$; they cannot be sold short. A tree pays $d_{t}^{e}$ units of dividend at date $t$. We summarize consumers' expectations about prices and dividends beyond period $t$ by specifying expectations about returns. In particular, we assume that consumers expect to earn a (random) real return $R_{\tau+1}^{e}$ by holding equity between any two periods $\tau$ and $\tau+1$, where $\tau \geq t$.

\section{Real Estate}

Real estate - or houses - may be thought of as trees that yield housing services. A consumer enters period $t$ with an endowment of $\bar{\theta}_{t}^{h} \geq 0$ units of houses. Houses trade at the ex-dividend price $p_{t}^{h}$; they cannot be sold short. To fix units, we assume that one unit of real estate (also referred to as one house) yields one unit of housing services at date $t$. There is a perfect rental market, where housing services can be rented at the price $p_{t}^{s}$. Moreover, every house requires a maintenance cost of $m$ units of numeraire. If a consumer buys $\theta_{t}^{h}$ units of real estate, he obtains a dividend $\left(p_{t}^{s}-m\right) \theta_{t}^{h}=: d_{t}^{h} \theta_{t}^{h}$. Consumers form expectations about future returns on housing and rental prices $\left\{R_{\tau}^{h}, p_{\tau}^{s}\right\}_{\tau>t}$

\section{Borrowing and Lending}

Consumers can borrow or lend by buying or selling one period discount nominal bonds. A consumer enters period $t$ with an endowment of $\bar{b}_{t}$ units of numeraire that is due to past borrowing and lending in the credit market. In particular, $\bar{b}_{t}$ is negative if the consumers has been a net borrower 
in the past. In period $t$, consumers can buy or sell bonds at a price $q_{t}$. A consumer expects every bond bought to pay $1 / \pi_{t+1}$ units of numeraire in period $t+1$. Here $\pi_{t+1}$ is random and may be thought of as the expected change in the dollar price of numeraire. This is a simple way to capture that debt is typically denominated in dollars. ${ }^{1}$ For every bond sold, the consumer expects to repay $(1+\xi) / \pi_{t+1}$ units of numeraire in period $t+1$, where $\xi>0$ is an exogenous credit spread. ${ }^{2}$ Bond sellers - borrowers - face a collateral constraint: the value of bonds sold may not exceed a fraction $\phi$ of the ex-dividend value of all real estate owned by the consumer. For periods $\tau>t$, consumers form expectations about the (random) real return on bonds $\left\{R_{\tau}^{b}\right\}$. They believe that $R_{\tau}^{b}=1 / q_{\tau-1} \pi_{\tau}$ is the (ex post) real lending rate, and that $R_{\tau}^{b}(1+\xi)$ is the (ex post) real borrowing rate.

\section{Non-Asset Income}

Consumers are endowed with an age-dependent stream of numeraire good $\left\{y_{\tau}\right\}_{\tau=t}^{t+T}$. Here income should be interpreted as the sum of labor income, transfer income, and income on illiquid assets such as private businesses.

\section{Budget Set}

The consumer enters period $t$ with an endowment of houses and equity $\left(\bar{\theta}_{t}^{h}, \bar{\theta}_{t}^{e}\right)$ as well as an endowment of $y_{t}+\bar{b}_{t}$ from non-asset income and past credit market activity. At period $t$ prices, initial wealth is therefore

$$
\bar{w}_{t}=\left(p_{t}^{h}+d_{t}^{h}\right) \bar{\theta}_{t}^{h}+\left(p_{t}^{e}+d_{t}^{e}\right) \bar{\theta}_{t}^{e}+\bar{b}_{t}+y_{t}
$$

To allocate this initial wealth to consumption and purchases of assets, the consumer chooses a plan $a_{t}=\left\{c_{t}, s_{t}, \theta_{t}^{h}, \theta_{t}^{e}, b_{t}^{+}, b_{t}^{-}\right\}$, where $b_{t}^{+} \geq 0$ and $b_{t}^{-} \geq 0$ denote the amount of bonds bought and sold, respectively. It never makes sense for a consumer to borrow and lend simultaneously, that is, $b_{t}^{+} \geq 0$ implies $b_{t}^{-}=0$ and vice versa.

\footnotetext{
${ }^{1}$ To see why, consider a nominal bond which costs $q_{t}$ dollars today and pays of $\$ 1$ tomorrow, or $1 / p_{t+1}^{c}$ units of numeraire consumption. Now consider a portfolio of $p_{t}^{c}$ nominal bonds. The price of the portfolio is $q_{t}$ units of numeraire and its payoff is $p_{t}^{c} / p_{t+1}^{c}=1 / \pi_{t+1}$ units of numeraire tomorrow. The model thus determines the price $q_{t}$ of a nominal bond in $\$$.

${ }^{2}$ One way to think about the organization of the credit market is that there is a financial intermediary that matches buyers and sellers in period $t$. In period $t+1$, the intermediary will collect $(1+\xi) / \pi_{t+1}$ units of numeraire from every borrower (bond seller), but pay only $1 / \pi_{t+1}$ to every lender (bond buyer), keeping $\xi / \pi_{t+1}$ for itself. We do not model the financial intermediary explicitly since we only clear markets in period $t$.
} 
The plan $a_{t}$ must satisfy the collateral constraint $q_{t} b_{t}^{-} \leq \phi p_{t}^{h} \theta_{t}^{h}$. The plan must also satisfy the budget constraint

$$
c_{t}+p_{t}^{s} s_{t}+w_{t}=\bar{w}_{t}
$$

where terminal wealth is defined as

$$
w_{t}=p_{t}^{h} \theta_{t}^{h}+p_{t}^{e} \theta_{t}^{e}+q_{t} b_{t}^{+}-q_{t} b_{t}^{-} .
$$

To formulate the budget constraint for periods beyond $t$, it is helpful to define the ex-dividend value of the consumer's stock portfolio in $t$ by $w_{t}^{e}=p_{t}^{e} \theta_{t}^{e}$, the consumer's real estate portfolio by $w_{t}^{h}=p_{t}^{h} \theta_{t}^{h}$ as well as the values of a (positive or negative) bond portfolio, $w_{t}^{b+}=q_{t} b_{t}^{+}$and $w_{t}^{b-}=q_{t} b_{t}^{-}$. For periods $\tau>t$, the consumer chooses plans $a_{\tau}=\left\{c_{\tau}, s_{\tau}, w_{\tau}^{h}, w_{\tau}^{e}, w_{\tau}^{b+}, w_{\tau}^{b-}\right\}$ subject to the collateral constraint $w_{\tau}^{b-} \leq \phi w_{\tau}^{h}$ and the budget constraint

$$
\begin{gathered}
c_{\tau}+p_{\tau}^{s} s_{\tau}+w_{\tau}^{h}+w_{\tau}^{e}+w_{\tau}^{b+}-w_{\tau}^{b-} \\
=R_{\tau}^{h} w_{\tau-1}^{h}+R_{\tau}^{e} w_{\tau-1}^{e}+R_{\tau}^{b} w_{\tau-1}^{b+}-R_{\tau}^{b}(1+\xi) w_{\tau-1}^{b-}+y_{\tau} .
\end{gathered}
$$

We denote the consumer's overall plan by $a=\left(a_{t},\left\{a_{\tau}\right\}_{\tau=t+1}^{t+T}\right)$. This plan is selected to maximize utility (2) subject to the budget constraints (3)-(5) and the collateral constraints.

Taxes

In some of our examples below, we will assume proportional income taxes as well as capital gains and dividend taxes. This will not change the structure consumer's problem, just the interpretation of the symbols. In particular, labor income, dividends and returns will have to be interpreted as their after-tax counterparts. Their precise form will be discuss in the calibration section below.

\section{Terminal Consumers}

The consumers described so far have planning horizons $T>0$. We also allow consumers with planning horizon $T=0$. These consumers also enter period $t$ with asset and numeraire endowments that provide them with initial wealth $\bar{w}_{t}$, as in (3). However, they do not make any savings or 
portfolio decisions. Instead, they simply purchase numeraire and housing services in the period $t$ goods markets to maximize (1) subject to the budget constraint

$$
c_{t}+p_{t}^{s} s_{t}=\bar{w}_{t} .
$$

\section{B. Equilibrium}

To capture consumer heterogeneity, we assume a finite number of consumer types, indexed by $i$, with different initial endowment vectors $\left(\bar{\theta}_{t}^{h}(i), \bar{\theta}_{t}^{e}(i), y_{t}(i)+\bar{b}_{t}(i)\right)$ and planning horizons $T(i)$.

\section{The Rest of the Economy}

To close the model and regulate the supply of assets exogenous to the household sector, we introduce a rest-of-the-economy (ROE) sector. It may be thought of as a consolidation of the business sector, the government and the rest of the world. The ROE sector is endowed with $f_{t}^{e}$ trees and $f_{t}^{h}$ houses in period $t$. Here $f_{t}^{e}$ could be negative to represent repurchases of shares by the corporate sector. In addition, the ROE enters period $t$ with an outstanding debt of $\bar{B}_{t}$ units of numeraire, and it raises $D_{t}$ units of numeraire by borrowing in period $t$. The surplus from these activities is

$$
C_{t}^{R O E}=f_{t}^{h}\left(d_{t}^{h}+p_{t}^{h}\right)+f_{t}^{e}\left(d_{t}^{e}+p_{t}^{e}\right)+D_{t}-\bar{B}_{t}
$$

If $C_{t}^{R O E}$ is positive, it is consumed by the ROE sector. More generally, the ROE is assumed to have "deep pockets" out of which it pays for any deficit if $C_{t}^{R O E}<0$.

Aggregate Asset Supply

We normalize initial endowments of equity and real estate such that there is a single tree and a single house outstanding:

$$
{ }_{i} \bar{\theta}_{t}^{h}(i)={ }_{i} \bar{\theta}_{t}^{e}(i)=1
$$

In addition, we assume that initial endowments from past credit market activity are consistent, in the sense that every position corresponds to some offsetting position, either by a household or by the ROE sector:

$$
{ }_{i} \bar{b}_{t}(i)=\bar{B}_{t}
$$




\section{Equilibrium}

An equilibrium consists of a vector of prices for period $t,\left(p_{t}^{h}, p_{t}^{e}, q_{t}, p_{t}^{s}\right)$, a surplus for the ROE sector $C_{t}^{R O E}$, as well as a collection of consumer plans for period $t,\left\{a_{t}(i)\right\}=\left\{c_{t}(i), s_{t}(i)\right.$, $\left.\theta_{t}^{h}(i), \theta_{t}^{e}(i), b_{t}^{+}(i), b_{t}^{-}(i)\right\}$ such that

(1) for every consumer, the plan $a_{t}(i)$ is part of an optimal plan $a(i)=\left(a_{t}(i),\left\{a_{\tau}(i)\right\}_{\tau=t+1}^{t+T(i)}\right)$ given consumer $i^{\prime} s$ endowment, planning horizon, and expectations about future prices and returns;

(2) markets for all assets and goods clear:

$$
\begin{aligned}
{ }_{i} \theta_{t}^{h}(i) & =1+f_{t}^{h}, \\
{ }_{i} \theta_{t}^{e}(i) & =1+f_{t}^{e}, \\
q_{t i} b_{t}^{+}(i) & =D_{t}+q_{t i} b_{t}^{-}(i), \\
{ }_{i} c_{t}(i)+m \theta_{t}^{h}(i)+C_{t}^{R O E} & ={ }_{i} y_{t}(i)+d_{t}^{e}\left(1+f_{t}^{e}\right), \\
{ }_{i} s_{t}(i) & ={ }_{i} \theta_{t}^{h}(i) .
\end{aligned}
$$

In addition to market clearing conditions for stocks, bonds and numeraire, there are two market clearing conditions for housing: one for the asset "real estate" and one for the good "housing services". The first equation ensures that the total demand for houses equals their total supply. The fifth equation ensures that the fraction of houses that owners set aside as investment real estate - that is, selling services in the rental market - is the same as the fraction of housing services demanded in the rental market. As is common in competitive models, one of the five market clearing conditions is redundant, as it is implied by the sum of consumers' budget constraints, the definition of $C_{t}^{R O E}$ and the other four market clearing conditions. Solving for equilibrium prices thus amounts to solving a system of four equation in the four prices $p_{t}^{h}, p_{t}^{e}, q_{t}$ and $p_{t}^{s}$. 


\section{Discussion of the Assumptions}

\section{Connection to National Income Accounting}

Introducing the ROE sector allows us to accommodate deviations between consumption and household sector income that are usually ignored in endowment economy models. To clarify the connection to the FFA/NIPA framework, we sum up the last three market clearing conditions and rearrange to obtain

$$
\underbrace{{ }_{i c_{t}(i)+p_{t}^{s} s_{t}(i)}}_{\text {personal consumption }}+\underbrace{f_{t}^{h} p_{t}^{h}+f_{t}^{e} p_{t}^{e}+D_{t}-q_{t-1} \bar{B}_{t}}_{\text {personal savings }}=\underbrace{{ }_{i} y_{t}(i)+d_{t}^{e}+d_{t}^{h}+\left(1-q_{t-1}\right) \bar{B}_{t}}_{\text {personal income }} .
$$

The first term on the left-hand side of this equation is personal consumption, including housing services. The right-hand side of this equation represents personal income. While our definition of income differs from the NIPAs in some details, as discussed in the next section, the basic components are the same: non-asset income, dividends on the two long-lived assets, and net interest. The difference between personal consumption and income is the second term on the left-hand side, which represents personal savings. It consists of the same components as in the FFA: net acquisition of real estate and net acquisition of financial assets, here equity and bonds. ${ }^{3}$ The supply of assets provided by the ROE thus allows for positive or negative personal savings in equilibrium.

\section{Asset Supply and Savings}

The possibility of nonzero savings makes our model compatible with richer models that explicitly consider production, fiscal policy, and the fact that the US is not a closed economy. A richer model would give rise to well-founded policy functions for the business, government, and foreign sectors that link those sectors' net asset supplies to market prices. At the same time, if the richer model accounts for observed supply by the ROE sector to the household sector, evaluating the policy functions at observed prices should deliver observed quantities. In our empirical implementation below, we thus set the net supply by the ROE equal to observed quantities.

\footnotetext{
${ }^{3}$ FFA savings is larger than our concept of savings because FFA investment contains investment in noncorporate business, as well as purchases of consumer durables. In our empirical implementation, noncorporate business is treated as illiquid and investment in it is subtracted from income. In addition, we follow the NIPA convention of treating expenditure on durables as consumption. This seems appropriate given the 6-year length of each period in our model.
} 
We thus determine asset prices such that households are willing to hold observed quantities, which would also be provided by the ROE in a well-working richer model. In a model where the other side of the market is also derived from optimal policies, the household sector could be modelled in exactly the same way as in our model. ${ }^{4}$ Hereby, we avoid a common criticism of asset pricing models based on endowment economies: model features that help explain prices in an endowment economy - for example, certain preference specifications - may entail undesirable outcomes once savings are allowed. Our strategy matches simultaneously prices and observed household savings.

Prices vs. Quantities

It is not common in endowment economy models to distinguish asset prices and quantities. Indeed, if the dividend from a single "tree" provides all consumption, there is no meaningful concept of quantity - doubling the quantity of trees is the same as doubling the dividend on the single tree. In our model, asset quantity is identified because we allow trades between the household sector and the ROE. Households increase or decrease the quantity of trees they own only through such trades. The change in quantity is determined by comparing the change in market capitalization with the capital gain on pre-existing trees. While a capital gain is enjoyed by households who enter the periods owning trees, a change in capitalization requires households to pay for new trees.

\section{Temporary Equilibrium}

Temporary equilibrium does not place restrictions on prices beyond date $t$ itself. In particular, it does not require that agents agree on a common model structure that links future fundamentals and prices. As far as household behavior is concerned, our empirical implementation instead follows the literature on portfolio choice, where exogenous processes for returns and income are standard. However, we go beyond portfolio choice models in that we explore how equilibrium prices change when investors' expectations about returns vary in a controlled way. This is particularly useful if expectations are matched to inflation surveys, as we do in Section VIII, since expected inflation directly affects returns.

\footnotetext{
${ }^{4}$ Our modelling strategy requires some care in interpretating counterfactuals. For example, computing the response to a change in tax rates cannot tell us what would have happened to the economy as a whole, since we do not model supply responses to tax changes. Instead, the counterfactual tells us what the household sector would have done if taxes changed, and what the effect on prices would have been had supply remained unchanged. The reason the exercise is still useful is that it allows us to see whether tax changes can play a first order role in accounting for asset prices over time, given the actual movements in equilibrium quantities.
} 
Our model does not link price expectations to future model-implied prices. Such a connection is imposed in rational expectations models, and more generally whenever agents have "structural knowledge" of the price function, such as in many models with Bayesian learning. Assuming structural knowledge has appeal when agents understand well how the economy works, for example because there are stable recurrent patterns in the data. Indeed, in a stationary environment, "knowing the price function" can be justified by learning from past data, and appears no more restrictive than "knowing the distribution of fundamentals."

However, our interest in this paper is in low frequency asset-price movements during times of structural change. In this context, it is not clear why agent beliefs should be based on the particular model structure that we consider today with the benefit of hindsight. For example, it is not clear whether household expectations should be required to anticipate structural change that we only now know to have taken place. Since the usual justifications for narrowing down the set of expectations by imposing rational expectations or structural knowledge is not compelling, we turn to flexible modelling of exogenous expectations.

\section{Connection to consumption-based asset-pricing}

Many studies that examine asset prices jointly with real variables focus on consumption, in particular the connection between consumption and asset prices implied by intertemporal Euler equations. Since our model is based on utility maximization, an Euler equation also holds, at least at the individual household level. Instead of considering temporary equilibria, thus deriving a map from endowments and supply to prices, one could consider examining the Euler equation directly. In certain ways this might be easier, since it requires only one non-price variable, consumption, although serious treatment of heterogeneous agents would require household-level consumption data.

The main problem with the Euler equation approach in our context is that the Euler equation relates prices to investors' planned consumption, and thus makes sense only if planned consumption can be measured. Imposing rational expectations effectively makes the (subjective) distribution of planned consumption measurable by setting it equal - by assumption - to the observed distribution of realized consumption. As discussed above, this is a strong assumption that is not compelling in the context of structural change. As a result, the Euler equation approach itself is not appealing for the application we consider in this paper. 
Table 1: Negative Net Worth Households

\begin{tabular}{c|cccccccccccc} 
& \multicolumn{4}{c}{$1962 \mathrm{SCF}$} & \multicolumn{4}{c}{$1995 \mathrm{SCF}$} & \multicolumn{4}{c}{2001 SCF } \\
& avg. & 29 & 53 & 77 & avg. & 29 & 53 & 77 & avg. & 29 & 53 & 77 \\
\hline \% of households & $4 \%$ & $10 \%$ & $3 \%$ & $2 \%$ & $7 \%$ & $18 \%$ & $4 \%$ & $2 \%$ & $7 \%$ & $20 \%$ & $5 \%$ & $2 \%$ \\
net worth (in \$) & $-.4 \mathrm{~K}$ & $-.4 \mathrm{~K}$ & $-.8 \mathrm{~K}$ & $-1.3 \mathrm{~K}$ & $-9 \mathrm{~K}$ & $-9 \mathrm{~K}$ & $-13 \mathrm{~K}$ & $-8 \mathrm{~K}$ & $-11 \mathrm{~K}$ & $-10 \mathrm{~K}$ & $-9 \mathrm{~K}$ & $-1 \mathrm{~K}$
\end{tabular}

Note: Row 1 reports the percentage of households with negative net worth in the U.S. population based on different SCFs. Row 2 reports the average net worth of these households in dollars.

Nonnegative Net Worth

Few households have negative net worth. Table 1 documents that the percentage of negative net worth households has always been between $4 \%$ and $7 \%$. Table 1 also shows that the net worth of these households is moderate. For example, the average net worth was -11K Dollars in 2001. These numbers suggest that the most important reason for household borrowing is not consumption smoothing. Instead, young households "borrow to gamble" — they borrow to be able to buy more risky assets, such as housing.

\section{The Role of Housing}

In both our model and in reality, housing plays a dual role: housing can be used for consumption and investment. In its role as consumption good, housing is different from other consumption, because it enters the utility function separately and has a different price $p_{t}^{s}$. In its role as asset, housing is different from other assets, because of its return properties (which will be discussed later), and because it can serve as collateral. In reality, the two roles are often connected, because the amount of housing services consumed is equal to the dividend paid by the amount of housing held in the portfolio. In our model, we abstract from this issue (at least for now) for several reasons. First, most homeowners not only own their primary residence, but also some investment real estate (such as time shares, vacation homes, secondary homes, etc.). Hence, there is no tight link between consumption and investment for these households. Second, U.S. households are highly mobile. As a consequence, houses are owned by the same owner on average for only seven years, which is roughly the same length as a period in our model. Moreover, the decision to move is often more or less exogenous to households (for example, because of job loss, divorce, death of the spouse, etc.). 


\section{Quantitative Implementation}

The inputs needed for implementing the model are $(i)$ the joint distribution of asset endowments and income, (ii) aggregate supply of assets to the household sector from other sectors, (iii) expectations about labor income and asset returns and $(i v)$ parameter values for preferences and the credit market. We describe our choices in detail in the Appendix; here we provide a brief overview. We start with a description of what a model period corresponds to in the data.

\section{Timing}

The length of a period is six years. Since the model compresses what happens over a six year span into a single date, prices and holdings are best thought of as period averages. We assume that consumers expect to live for at most 10 such periods, where the first period of life corresponds roughly to the beginning of working life. In any given period, we consider 11 age groups of households $(<23,24-29,30-35,36-41,42-47,48-53,54-59,60-65,66-71,72-77,>77)$ who make portfolio choice decisions. For ease of comparison with other models, we nevertheless report numbers at annual rates.

In the time series dimension, we focus on three six-year periods, namely 1965-70, 1975-80, and 1992-97. To construct asset endowment distributions, we use data on asset holdings from the respective precursor periods 1959-64, 1969-74, and 1986-91. Micro data is not available at high frequencies. To capture the wealth and income distribution during a period, we have chosen the above intervals so that every period that contains a Survey of Consumer Finances contains it in the 4th year of the period; we thus use surveys from 1962, 1989 and 1995. We use the 4th year survey to infer income and asset holdings where possible.

\section{A. Defining Assets and Income}

We map the three assets in the model to three broad asset classes in US aggregate and household statistics. For equity and real estate, we use the Flow of Funds Accounts (FFA) to derive measures of $(i)$ aggregate holdings of the household sector, $(i i)$ net purchases by the household sector and (iii) aggregate dividends received by the household sector. We use the numbers on value, dividends and new issues to calculate price dividend ratios and holding returns on equity and real estate. For both 
assets, we also define corresponding measures at the individual level using the Survey of Consumer Finances (SCF).

Equity

We identify equity with shares in corporations held and controlled by households. We include both publicly traded and closely held shares, and both foreign and domestic equity. We also include shares held indirectly through investment intermediaries if the household can be assumed to control the asset allocation (into our broad asset classes) himself. We take this to be true for mutual funds and defined contribution (DC) pensions plans. We do not include equity in defined benefit (DB) pension plans, since households typically do not control the asset allocation of such funds. Our concept of dividends thus equals dividends received by households from the National Income and Product Accounts (NIPA) less dividends on household holdings in DB plans.

\section{Real estate}

Our concept of residential real estate contains owner-occupied housing, directly held residential investment real estate, as well as residential real estate recorded in the FFA/NIPA as held indirectly by households through noncorporate businesses. This concept contains almost all residential real estate holdings, since very few residential properties are owned by corporations. We take housing dividends to be housing consumption net of maintenance and property tax from NIPA. For net purchases of new houses, we use aggregate residential investment from NIPA.

The ROE sector endowment of equity consists of net new equity purchased by the household sector during the trading period. The factor $f^{e}$ states this endowment relative to total market capitalization in the model. We thus use net purchases of corporate equity divided by total household holdings of corporate equity. The ROE sector endowment of residential real estate consists of residential investment, divided by the value of residential real estate. The top panel of Figure 4 plots quarterly series for both ROE endowment, or "asset supply" numbers. The calibration of the model uses six-year averages of these series.

\section{Nominal positions}

Our concept for a household's bond holdings is its net nominal position, that is, the market value of all nominal assets minus the market value of nominal liabilities. As for equity, holdings include 
New supply of long-lived assets (\% market cap)
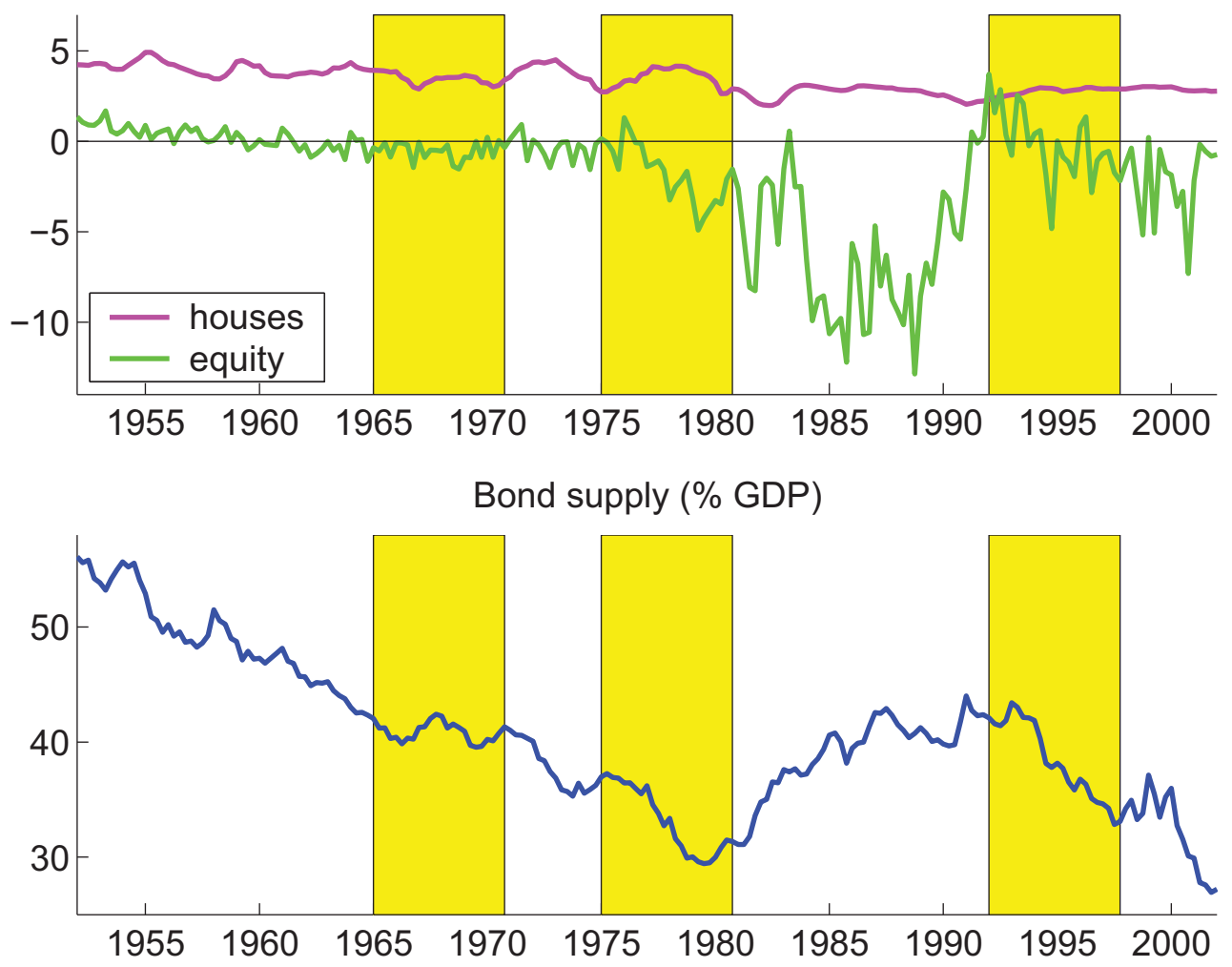

Figure 4: Top panel: Net new corporate equity as a percent of total household holdings of corporate equity and residential investment as percent of value of residential real estate. Data are quarterly at annual rates. Bottom panel: Net nominal position of household sector as a percent of GDP.

not only direct holdings, but also indirect holdings through investment intermediaries. To calculate market value, we use the market value adjustment factors for nominal positions in the U.S. from Doepke and Schneider (2006). In line with our treatment of tenant-occupied real estate, we assign residential mortgages issued by noncorporate businesses directly to households.

When considering gross nominal positions, we must take into account the fact that some netting of positions occurs at the individual level. A typical household will have both a mortgage loan or credit card and a savings account or bonds in a pension fund. However, the model has only one type of nominal asset, and a household can be either long or short that asset. If we were to match the gross aggregates from the FFA or SCF in our model, this would inevitably lead to net positions that are too large. Instead, we sort SCF households into borrowers and lenders, according to whether their net nominal position is negative or not. The numbers for gross borrowing and lending are then calculated as minus the sum of net nominal positions of borrowers as well as the sum of net positions 
of all lenders, respectively.

Table 2 summarizes these gross nominal positions after individual netting from the SCF and compares them to those in the FFA. Both the FFA numbers and our estimates reflect a steady increase in borrowing by the household sector. At the same time, both sets of numbers show a reduction in nominal asset holdings in the 1970s followed by an increase between 1978 and 1995 . Throughout, individual netting reduces gross lending by roughly one third, while it reduces gross borrowing by slightly more than half.

\begin{tabular}{ccccccc}
\multicolumn{6}{c}{ TABle 2: Gross BorRowing AND Lending (\%GDP) } \\
& \multicolumn{2}{c}{1968} & \multicolumn{2}{c}{1978} & \multicolumn{2}{c}{1995} \\
& lending & borrowing & lending & borrowing & lending & borrowing \\
\hline FFA aggregates & 88 & 47 & 84 & 51 & 107 & 68 \\
SCF after indiv. netting & 61 & 20 & 56 & 23 & 70 & 31
\end{tabular}

The initial nominal position of the ROE sector is taken to be minus the aggregate (updated) net nominal position of the household sector. Finally, the new net nominal position of the ROE in period $t$ - in other words, the "supply of bonds" to the household sector - is taken to be minus the aggregate net nominal positions from the FFA for period $t$. This series is reproduced in the bottom panel of Figure 4.

Non-Asset Income

Our concept of non-asset income comprises all income that is available for consumption or investment, but not received from payoffs of one of our three assets. We construct an aggregate measure of such income from NIPA and then derive a counterpart at the household level from the SCF. Of the various components of worker compensation, we include only wages and salaries, as well as employer contributions to DC pension plans. We do not include employer contributions to DB pension plans or health insurance, since these funds are not available for consumption or investment. However, we do include benefits disbursed from DB plans and health plans. Also included are transfers from the government. Finally, we subtract personal income tax on non-asset income. 


\section{B. The joint distribution of asset endowments and income}

Consumers in our model are endowed with both assets and non-asset income. To capture decisions made by the cross-section of households, we thus have to initialize the model for every period $t$ with a joint distribution of asset endowment and income. We derive this distribution from data on terminal asset holdings and income in the precursor period $t-1$. To handle multidimensional distributions, we approximate them by a finite number of household types. Types are selected to retain key moments of the full distribution, in particular aggregate gross borrowing and lending.

Since the aggregate endowment of long-lived assets is normalized to one, we can read off the endowment of a household type in period $t$ from its market share in period $t-1$. For each long-lived asset $a=h, e$, suppose that $w_{t-1}^{a}(i)$ is the market value of investor $i$ 's position in $t-1$ in asset $a$. Its initial holdings are given by

$$
\begin{aligned}
\bar{\theta}_{t}^{a}(i) & =\theta_{t-1}^{a}(i)=\frac{w_{t-1}^{a}(i)}{{ }_{i} w_{t-1}^{a}(i)}=\frac{p_{t-1}^{a} \theta_{t-1}^{a}(i)}{p_{t-1}^{a} \theta_{t-1}^{a}(i)} \\
& =\text { market share of household } i \text { in period } t-1
\end{aligned}
$$

For nominal assets, the above approach does not work since these assets are short-term in our model. Instead, we determine the market value of nominal positions in period $t-1$ and update it to period $t$ by multiplying it with a nominal interest rate factor:

$$
\begin{aligned}
\bar{b}_{t}(i) & =\left(1+i_{t-1}\right) \frac{w_{t-1}^{b}(i)}{\mathrm{GDP}_{t}} \\
& =\left(1+i_{t-1}\right) \frac{w_{t-1}^{b}(i)}{{ }_{i} w_{t-1}^{b}(i)} \frac{i w_{t-1}^{b}(i)}{\operatorname{GDP}_{t-1}} \frac{\mathrm{GDP}_{t-1}}{\mathrm{GDP}_{t}}
\end{aligned}
$$

Letting $g_{t}$ denote real GDP growth and $D_{t}$ the aggregate net nominal position as a fraction of GDP, we have

$$
\bar{b}_{t}(i) \approx \bar{\theta}_{t-1}^{b}(i) D_{t-1}\left(1+i_{t-1}-g_{t}-\pi_{t}\right)
$$

This equation distinguishes three reasons why $\bar{b}_{t}(i)$ might be small in a given period. The first is simply that the household's nominal investment in the previous period was small. Since all endowments are stated relative to GDP, all current initial nominal positions are also small if the economy has 
just undergone a period of rapid growth. Finally, initial nominal positions are affected by surprise inflation over the last few years. If the nominal interest rate $i_{t-1}$ does not compensate for realized inflation $\pi_{t}$, then $\bar{b}_{t}^{i}$ is small (in absolute value). Surprise inflation thus increases the negative position of a borrower, while it decreases the positive position of a borrower.

The final step in our construction of the joint income and endowment distribution is to specify the marginal distribution of non-asset income. Here we make use of the fact that income is observed in period $t-1$ in the SCF. We then assume that the transition between $t-1$ and $t$ is determined by a stochastic process for non-asset income. We employ the same process that agents in the model use to forecast their non-asset income, described in Appendix B. This approach allows to capture the correlation between income and initial asset holdings that is implied by the joint distribution of income and wealth.

Distributions for 1968, 1978 and 1995

Figure 5 provides summary information on asset endowment and income distributions in the three trading periods we consider below. The trading periods are identified in the figure by their respective fourth year: 1968, 1978 and 1995. The top left panel provides population weights by cohort. Cohorts are identified on the horizontal axis by the upper bound of the age range. In addition, the fraction of households that exit during the period are offset to the far right.

The different years can be distinguished by the line type: solid with circles for 1968, dashed with squares for 1978 and dotted with diamonds for 1995. Using the same symbols, the top right panel shows house endowments (light lines) and stock endowments (dark lines) by age cohort, while the bottom left panel shows initial net nominal positions as a percent of GDP. Finally, the bottom right panel shows income distributions. Here we plot not only non-asset income, but also initial wealth not invested in long-lived assets, in other words,

$$
E_{t}=d_{t}^{h} \bar{\theta}_{t}^{h}+d_{t}^{e} \bar{\theta}_{t}^{e}+\bar{b}_{t}+y_{t} .
$$

This aggregate will be useful to interpret the results below.

Two demographic changes are apparent from the figure. First, the baby boom makes the two youngest cohorts relatively larger in the 1978 cross section than in the other two years. By 1995, the 

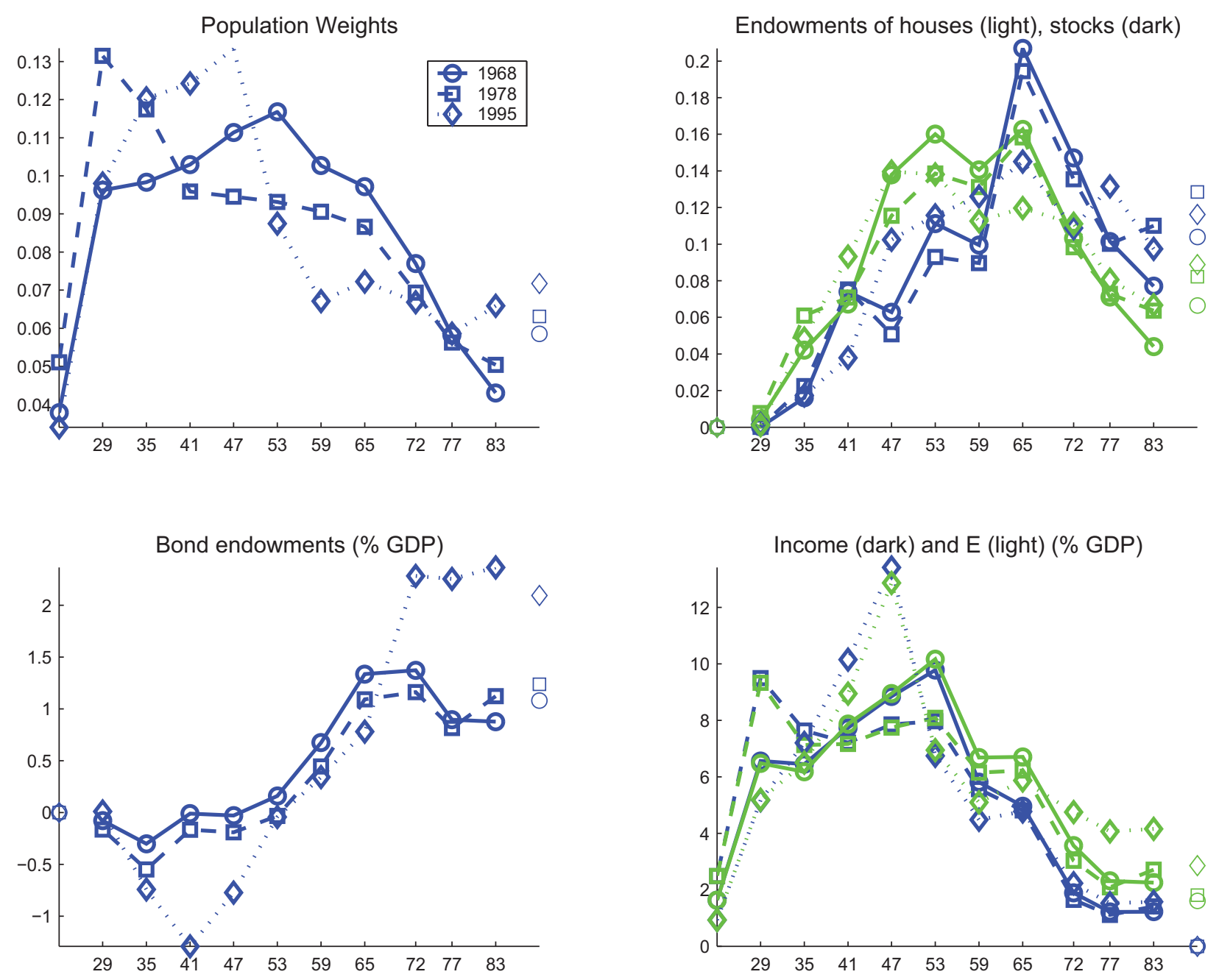

Figure 5: Asset endowment and income distributions in 1968, 1978 and 1995. Top left panel: Population weights by cohort, identified on the horizontal axis by the upper bound of the age range. Exiting households during the period are on the far right. Top right panel: House endowments (light lines) and stock endowments (dark lines) by age cohort. Bottom left panel: initial net nominal positions as a percent of GDP. Bottom right panel: Income distributions.

boomers have aged so that the $42-47$ year olds are the now strongest cohort. This shift of population shares is also reflected in the distribution of income in the bottom right panel. Second, the relative size of the oldest group has become larger over time. Recently, a lot of retirement income comes from assets, so that the share of $E_{t}$ of the elderly groups has also increased a lot. A key difference between the 1968 and 1978 distributions is thus that the latter places more weight on households who tend to save little: the oldest and, especially, the youngest. While the 1995 distribution also has relatively more weight on the elderly, it emphasizes more the middle-aged rather than the young. 
The comparison of stock and house endowments in the top right panel reveals that housing is more of an asset for younger people. For all years, the market shares of cohorts in their thirties and forties are larger for houses than for stocks, while the opposite is true for older cohorts. By and large, the market shares are however quite similar across years. In contrast, the behavior of net nominal positions relative to GDP (bottom right hand panel) has changed markedly over time. In particular, the amount of intergenerational borrowing and lending has increased: young households today borrow relatively more, while old households hold relatively more bonds.

\section{Expectations and Preference Parameters}

A baseline set of beliefs for returns and non-asset income is derived in Appendix B. We assume that consumers believe real asset returns and aggregate growth to be serially independent over successive six year periods. Moreover, consumers believe that returns and growth are identically distributed for periods beyond $t+1 .^{5}$ To pick numbers, we start from empirical moments of six-year ex-post pre-tax real returns on fixed income securities, residential real estate and equity, as well as inflation and growth. Since returns on individual properties are more volatile than those on a nationwide housing index, we add an idiosyncratic shock to the house return faced by an individual household.

We also specify a stochastic process for after-tax income. Briefly, the functional form for this process is motivated by existing specifications for labor income that employ a deterministic trend to capture age-specific changes in income, as well as permanent and transitory components. We also use estimates from the literature to account for changes in the volatility of the different components over time.

As for preference parameters, the intertemporal elasticity of substitution is $\sigma=.5$, the coefficient of relative risk aversion is $\gamma=5$ and the discount factor is $\beta=\exp (-0.025 \times 6)$. Since $\gamma$ is low, agents do not want to hold bonds when faced with historical Sharpe ratios on stocks and housing. To avoid this counterfactual implication, we assume that agents view long-lived assets as riskier than indicated by their historical moments. This idea of "low aversion against high perceived risk" can be captured by scaling the historical return variances from Table B.2 with a fixed number. This scaling

\footnotetext{
${ }^{5}$ In most of the exercises below, we allow beliefs for returns between $t$ and $t+1$ to differ from baseline beliefs, so that returns are not iid. We discuss the latter aspect of beliefs below when we present our results.
} 
can be interpreted as a consequence of Bayesian learning about the premium on equity and housing. We select a factor of 3 , which leads to match the aggregate portfolio weights for 1995 reported in Table 3 almost exactly.

TABle 3: 1995 Data And Baseline Beliefs

\begin{tabular}{|c|c|c|c|c|c|c|c|c|c|}
\hline \multirow[t]{2}{*}{ experiment } & \multirow{2}{*}{$\begin{array}{c}\text { wealth/ } \\
\text { GDP }\end{array}$} & \multicolumn{3}{|c|}{ portfolio weights } & \multirow{2}{*}{$\begin{array}{l}\text { lend./ } \\
\text { GDP }\end{array}$} & \multirow{2}{*}{$\begin{array}{l}\text { borr/ } \\
\text { GDP }\end{array}$} & \multicolumn{2}{|c|}{$\mathrm{PD}$ ratios } & \multirow{2}{*}{$\begin{array}{c}\text { interest rate } \\
\text { nominal }\end{array}$} \\
\hline & & bonds & housing & stocks & & & housing & stocks & \\
\hline (1) -1995 data - & 2.51 & .15 & .59 & .26 & .70 & .31 & 20.4 & 23.9 & .061 \\
\hline (2) baseline & 2.51 & .15 & .60 & .25 & .70 & .31 & 20.8 & 22.7 & .061 \\
\hline
\end{tabular}

NOTE: The first row reports the aggregate portfolio weights on bonds, housing and stocks from Figure 2; the gross borrowing and lending numbers from Section A., the wealth-to-GDP ratio from Figure 1; the price-dividend ratios for housing and stocks together with the nominal 6-year interest rate. The second row report the results computed from the model for 1995 with baseline beliefs.

An alternative strategy would be to work with agents who have "high aversion against low perceived risk." In this case, agents base their portfolio choice on the historical variances from Table B.2, but are characterized by high risk aversion, $\gamma=25$, and high discounting, $\beta=\exp (-0.07 \times 6)$. The high $\gamma$ is needed to lower the portfolio weight on bonds, while the low $\beta$ is needed to reduce the precautionary savings motive in the presence of uninsurable income shocks. While the tables below report results based on agents with "low aversion against high perceived risk," we would get results comparable to those in Table 3 based on this alternative parametrization. ${ }^{6}$

\section{Taxes and the Credit Market}

It remains to select parameters to capture taxes on investment as well as consumers' opportunities for borrowing. For the year 1995, we assume a $2 \%$ per year spread between borrowing and lending interest rates. Early on, credit markets were less developed and gross credit was thus smaller. To capture this, we set the spread to $2.75 \%$ for the earlier years. In addition, we select the borrowing

\footnotetext{
${ }^{6}$ Yet another way to obtain realistic aggregate portfolio weights is to combine low risk aversion with first-time participation costs, as shown by Gomes and Michaelides (2005).
} 
constraint parameter $\phi=.8$. This implies a maximal loan-to-value ratio of $80 \%$, where "value" is the ex-dividend value of the house.

Investors care about after-tax real returns. In particular, taxes affect the relative attractiveness of equity and real estate. On the one hand, dividends on owner-occupied housing are directly consumed and hence not taxed, while dividends on stocks are subject to income tax. On the other hand, capital gains on housing are more easily sheltered from taxes than capital gains on stocks. This is because many consumers simply live in their house for a long period of time and never realize the capital gains. Capital gains tax matters especially in inflationary times, because the nominal gain is taxed: the effective real after tax return on an asset subject to capital gains tax is therefore lower when inflation occurs.

To measure the effect of capital gains taxes, one would ideally like to explicitly distinguish realized and unrealized capital gains. However, this would involve introducing state variables to keep track of past individual asset purchase decisions. To keep the problem manageable, we adopt a simpler approach: we adjust our benchmark returns to capture the effects described above. For our baseline set of results, we assume proportional taxes, and we set both the capital gains tax rate and the income tax rate to $20 \%$. We define after tax real stock returns by subtracting $20 \%$ from realized net real stock returns and then further subtracting $20 \%$ times the realized rate of inflation to capture the fact that nominal capital gains are taxed. In contrast, we assume that returns on real estate are not taxed.

\section{Household Behavior}

In this section, we consider savings and portfolio choice in the cross section of households. We focus on baseline beliefs for 1995, the year we have used to calibrate beliefs. The initial distribution of asset endowments and income is derived from the $1989 \mathrm{SCF}$, as discussed in Section IV. We first

present optimal policies as functions of wealth and income. We then compare the predictions of the model for the cross-section of households in 1995 to actual observations from the 1995 SCF. 


\section{A. Lifecycle Savings and Portfolios}

Since preferences are homothetic and all constraints are linear, the optimal savings rate and portfolio weights depend only on age and the ratio of initial wealth $\bar{w}_{t}$ - defined in (3) above as asset wealth plus non-asset income - to the permanent component of non-asset income, say $\hat{y}_{t}$. For simplicity, we refer to $\bar{w}_{t} / \hat{y}_{t}$ as the wealth-to-income ratio. Figure 6 plots agent decisions as a function of this wealth-to-income ratio.

Savings

The bottom right panel shows the ratio $w_{t} / \bar{w}_{t}$ of terminal wealth to initial wealth, that is, the savings rate out of initial wealth. Savings are always positive, since the borrowing constraint precludes strategies that involve negative net worth. Investors who have more income in later periods than in the current period thus cannot shift that income forward by borrowing. In this sense, there is no borrowing for "consumption smoothing" purposes: all current consumption must instead come out of current income or from selling initial asset wealth.

If initial wealth is very low relative to income, all assets will be sold and all income consumed, so that the investor enters the next period with zero asset wealth. As initial wealth increases, a greater fraction of it is saved for future consumption. In the absence of labor income, our assumption of serially independent returns implies a constant optimal savings rate. As wealth becomes large relative to the permanent component of income, the savings rate converges to this constant.

The bottom right panel also illustrates how the savings rate changes with age. There are two relevant effects. On the one hand, younger investors have a longer planning horizon and therefore tend to spread any wealth they have over more remaining periods. This effect by itself tends to make younger investors save more. On the other hand, the non-asset income profile is hump-shaped, so that middle-aged investors can rely more on labor income for consumption than either young or old investors. This tends to make middle-aged investors save relatively more than other investors.

The first effect dominates when labor income is not very important, that is, when the wealthto-income ratio is high. The figure shows that at high wealth-to-income ratios, the savings rate of the 29-35 year old group climbs beyond that of the oldest investor group. It eventually also climbs below the savings rate of the 48-53 year old group. The second effect is important for lower wealth- 

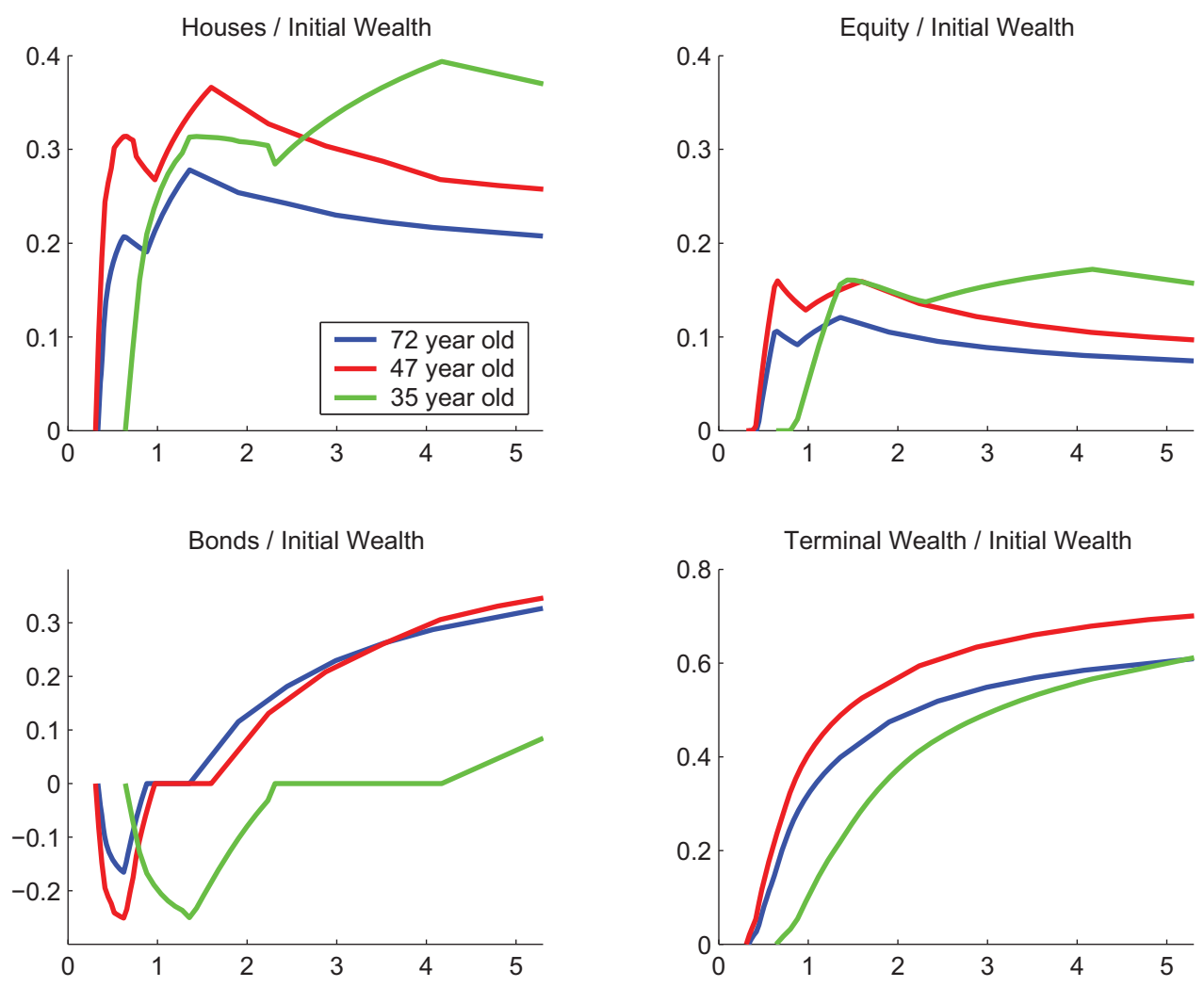

Figure 6: Asset holdings and terminal wealth, both as fractions of initial wealth, plotted against the initial wealth-to-income ratio. Age groups are identified by maximum age in the cohort.

to-income ratios, especially in the empirically relevant range around 1-2, where most ratios lie in the data. In this region, the savings rate of the middle-aged is highest, whereas both the young and the old save less. Among the latter two groups, the young save the least when their wealth-to-income ratio is low.

\section{Borrowing and Leverage}

Rather than enable consumption smoothing, the role of borrowing in our model is to help households construct leveraged portfolios. The bottom left panel of Figure 6 shows that investors who are younger and have lower wealth-to-income ratios tend to go short in bonds. The top panels show that the borrowed funds are used to build leveraged positions of houses and also stocks. In contrast, investors who are older and have higher wealth-to-income ratios tend to go long in all three assets. Along the wealth-to-income axis, there is also an intermediate region where investors hold zero bonds. This region is due to the credit spread: there exist ratios where it is too costly to leverage at the 
high borrowing rate, while it is not profitable to invest at the lower lending rate.

The reason why "gambling" with leverage decreases with age and the wealth-to-income ratio is the presence of labor income. Effectively, an investor's portfolio consists of both asset wealth and human wealth. Younger and lower wealth-to-income households have relatively more human wealth. Moreover, the correlation of human wealth and asset wealth is small. As a result, households with a lot of labor income hold riskier strategies in the asset part of their portfolios. This effect has also been observed by Jagannathan and Kocherlakota (1996), Heaton and Lucas (2000), and Cocco (2005).

Stock v. House Ownership

For most age groups and wealth-to-income ratios, investment in houses is larger than investment in stocks. This reflects the higher Sharpe ratio of houses as well as the fact that houses serve as collateral while stocks do not. The latter feature also explains why the ratio of house to stock ownership is decreasing with both age and wealth-to-income ratio: for richer and older households, leverage is less important, and so the collateral value of a house is smaller.

The model can currently not capture the fact that the portfolio weight on stocks tends to increase with the wealth-to-income ratio. While it is true in the model that people with higher wealth-toincome own more stocks relative to housing, they also hold much more bonds relative to both of the other assets. As a result, their overall portfolio weight on stocks actually falls with the wealthto-income ratio. The behavior of the portfolio weight on stocks implies that the model produces typically too little concentration of stock ownership.

\section{B. The Cross Section of Asset Holdings}

Figure 7 plots predicted portfolio weights and market shares for various groups of households for 1995, given baseline beliefs. The panels also contain actual weights and market shares for the respective groups from the $1995 \mathrm{SCF}$. It is useful to compare both portfolio weights and market shares, since the latter also require the model to do a good job on savings behavior. Indeed, defining aggregate initial wealth $\bar{W}={ }_{i} \bar{w}(i)$, the market share of asset $a=h, e$ for a household $i$ can be written as

$$
\theta^{a}(i)=\frac{\alpha^{a}(i) \bar{w}(i)}{{ }_{i} \alpha^{a}(i) \bar{w}(i)}=\frac{\alpha^{a}(i)}{{ }_{i} \alpha^{a}(i) \frac{\bar{w}(i)}{\bar{W}}} \frac{\bar{w}(i)}{\bar{W}}=\frac{\alpha^{a}(i)}{\bar{\alpha}^{a}} \frac{\bar{w}(i)}{\bar{W}},
$$


where $\alpha^{a}(i)$ is household $i$ 's portfolio weight and $\bar{\alpha}^{a}$ is the aggregate portfolio weight on asset $a$. A model that correctly predicts the cross section of portfolio shares will therefore only correctly predict the cross section of market shares if it also captures the cross section of terminal wealth. The latter in turn depends on the savings rate of different groups of agents.

The first row of Figure 7 documents savings behavior by cohort and wealth level. The top left panel plots terminal wealth as a fraction of GDP at the cohort level (blue/black lines) for the model (dotted line) and the data (solid line). It also shows separately terminal wealth of the top decile by net worth (green/light gray lines), again for the model and the data. This color coding of plots is maintained throughout the figure, so that a "good fit" means that the lines of the same color are close to each other.

The top left panel shows that model does a fairly good job at matching terminal wealth. The model also captures skewness of the distribution of terminal wealth and how this skewness changes with age. The top $10 \%$ by net worth own more than half of total terminal wealth, their share increasing with age. In the model, these properties are inherited in part from the distributions of endowment and labor income. However, it is also the case that richer agents save more out of initial wealth. This feature is apparent from the top right panel of Figure 7 which reports savings rates by cohort and net worth. It obtains because $(i)$ the rich have higher ratios of initial wealth relative to current labor income, and $(i i)$ the savings rate is increase with the wealth-to-income ratio, as explained in the previous subsection.

In the data, the main difference in portfolio weights by age is the shift from houses into bonds over the course of the life cycle. This is documented in the right column of Figure 7. Young agents borrow in order to build leveraged positions in houses. In the second panel, their portfolio weights become positive with age as they switch to being net lenders. The accumulation of bond portfolios makes houses - shown in the third panel on the right - relatively less important for older households. The model captures this portfolio shift fairly well. Intuitively, younger households "gamble" more, because the presence of future labor income makes them act in a more risk tolerant fashion in asset markets.

The left column shows the corresponding cohort aggregates. Nominal positions relative to GDP (second panel on the left) are first negative and decreasing with age, but subsequently turn around 

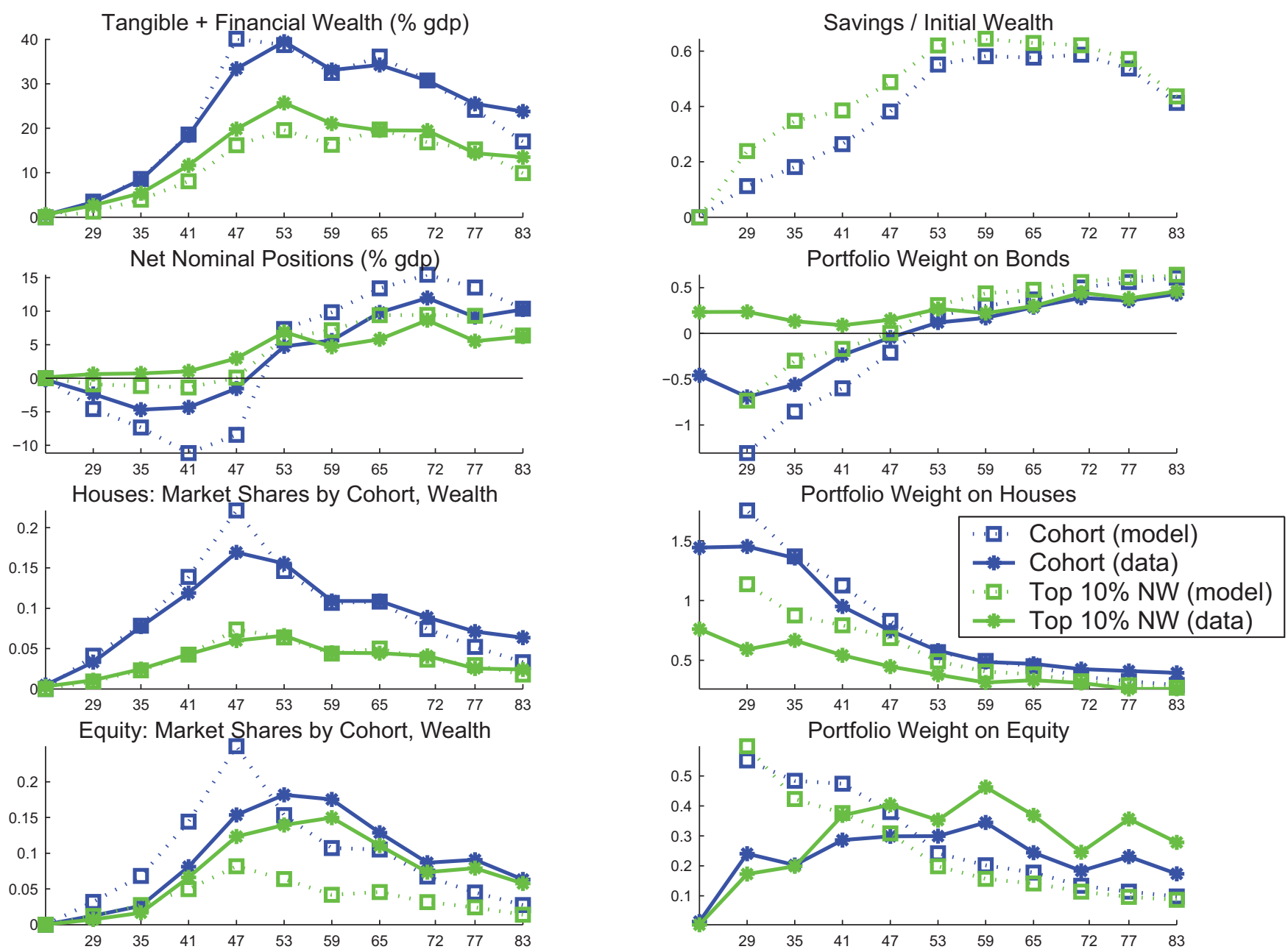

Figure 7: Market shares and portfolio weights for 1995

and increase with age so that they eventually become positive. These properties are present both in the model and the data. On the negative side, the model somewhat overstates heterogeneity in positions by age: there is too much borrowing - and too much investment in housing - by young agents. In particular, the portfolio weights for the very youngest cohort are too extreme. However, since the wealth of this cohort is not very large, its impact on aggregates and market shares is small.

For houses (third panel on the left), the combination of portfolio and savings choices generate a hump shape in market share. While younger agents have much higher portfolio weights on real estate than the middle-aged, their overall initial wealth is sufficiently low, so that their market share is lower than that of the middle-aged. Another feature of the data is that the portfolio shift from housing 
to bonds with age is much less pronounced for the rich. The model also captures this feature, as shown by the green/gray lines in the second and third rows of the figure. The intuition again comes from the link between leverage and the wealth-to-income ratio: the rich are relatively asset-rich (high wealth-to-income) and thus put together less risky asset portfolios, which implies less leverage and lower weights on housing.

The panels in the last row of Figure 7 plot market shares and portfolio weights for equity. This is where the model has the most problems replicating the SCF observations. Roughly, investment in stocks in the model behaves "too much" like investment in housing. Indeed, the portfolio weight is not only decreasing with age after age 53 , as in the data, but it is also decreasing with age for younger households. As a result, while the model does produce a hump-shaped market share, the hump is too pronounced and occurs at too young an age. In addition, the model cannot capture the concentration of equity ownership in the data: the rich hold relatively too few stocks.

\section{Asset Prices in Temporary Equilibrium}

In this section, we consider the temporary equilibrium map from model inputs - the distribution of endowments and income, asset supply, and expectations - into equilibrium prices. We report counterfactual experiments, based on the 1995 distribution, to illustrate the mechanics of the model and the relative magnitude of key effects.

\section{Price Determination}

To organize the discussion, we use the following equations, derived from the market clearing conditions and the household budget constraints. Dropping time subscripts to simplify notation, we have

$$
\begin{aligned}
p^{a}\left(1+f^{a}\right) & ={ }_{i} \alpha^{a}(\bar{w}(i) / \hat{y}(i) ; i, q) \bar{w}(i) ; \quad a=h, e . \\
p^{h}\left(1+f^{h}\right)+p^{e}\left(1+f^{e}\right)+D & ={ }_{i} S(\bar{w}(i) / \hat{y}(i) ; i, q) \bar{w}(i) .
\end{aligned}
$$

The aggregate value of long-lived asset $a$ (where $a=h$ or $e$ ) must equal, in equilibrium, the value of household demand for the asset. At the level of the individual household, asset demand can be 
written as the product of initial wealth $\bar{w}(i)$ and the asset weight $\alpha^{a}$. The latter was shown in Figure 6 as a function of the wealth-to-income ratio $\bar{w}(i) / \hat{y}(i)$. It also depends on other household characteristics such as age and expectations, as well as on the market interest rate, or equivalently the bond price $q \cdot{ }^{7}$ The second equation says that the value of all assets held by households - in our empirical framework, the numerator of the wealth-GDP ratio - must equal total household savings, where the savings rate, shown in the bottom right panel of Figure 6, is denoted $S$.

Equations (7) implicitly determine the three asset prices $q, p^{e}$ and $p^{h}$ as a function of supply, endowments and expectations, where the latter enter through the portfolio weight functions $\alpha^{a}$ and the savings rate function $S$. The second equation can be written as

$$
\begin{aligned}
p^{h}\left(1+f^{h}\right)+p^{e}\left(1+f^{e}\right)+D & ={ }_{i} \frac{\bar{w}(i)}{{ }_{i} \bar{w}(k)} S\left(\bar{w}(i) / \hat{y}(i) ; i, q_{t}\right){ }_{i} \bar{w}(k) \\
& =\bar{S}\left(p^{h}+p^{e}+E\right)
\end{aligned}
$$

where $\bar{S}$ is the initial-wealth-weighted average savings rate and $E$ is aggregate initial wealth not invested in long-lived assets, as defined in (6).

Suppose for the moment that new asset supply is the same for equity and houses, that is, $f^{e}=$ $f^{h}=f$. The intuition generated by this case is helpful for interpreting our results more generally. The aggregate value of these assets now becomes

$$
p^{h}+p^{e}=\frac{\bar{S} E-D}{1+f-\bar{S}}
$$

Other things - including expectations - equal, the value of long-lived assets decreases when the ROE supplies more of these assets. It also decreases when the ROE raises more funds in the bond market. Here it matters that our calibration strategy takes the market value of bond supply as given (rather than, say, the face value). Higher bond supply in our exercises always subtracts a fixed amount from the demand for other savings vehicles, such as houses and equity and thus lowers the value of those vehicles. Finally, the value of long-lived assets increases with any event that increased the average savings rate in the household sector. In particular, it depends on household expectations

\footnotetext{
${ }^{7}$ Asset demand depends on the prices of long-lived assets only through the effects of those prices on initial wealth. The reason is that return expectations are exogenous, execpt for bonds where they depend on the market interest rate and expected inflation.
} 
only through their effect on the average savings rate.

An important implication of equation (8) is that the total value of long-lived assets is determined by consumption-savings considerations, not by portfolio choice considerations. Indeed, at the household level, the optimal savings rate is chosen to smooth consumption over time, given the total return on wealth. In contrast, the weights $\alpha$ on the individual assets are chosen to generate the highest possible total return on wealth, trading off risk and return. The total value of long-lived assets depends strongly on aspects of the household problem that affect the savings decision, such as the discount factor, the intertemporal elasticity of substitution, the age distribution and expectations of labor income growth. It is less sensitive to factors that matter for portfolio choice, such as the relative returns on different assets. The latter factors are instead important for the individual asset prices, as well as the bond price, which must adjust to ensure that all three equations in (7) hold.

\section{Counterfactuals from the 1995 baseline}

Table $3 \mathrm{~A}$ illustrates the sensitivity of asset prices to changes in expectations and asset supply. The main result is that events relevant to the stock market spill over much less into other asset markets than events relevant to the housing market, although stock prices are themselves more responsive to changes in expectations. Rows 2 and 3 compare one percent increases in the expected return on stocks and houses, respectively. Since these changes affect the relative attractiveness of assets, they have only a small (positive) effect on savings and hence the wealth-GDP ratio. However, they do give rise to significant portfolio shifts and price changes.

Row 2 shows that a one percent increase in real stock return expectations over the next six years raises the price dividend ratio of stocks by $15 \%$, but raises the nominal interest rate by only 10 basis points; it lowers the price-dividend ratio on housing by 3.5\%. In contrast, row 3 shows that a one percent increase in the expected return on real estate raises the house price by $7 \%$, increases the nominal interest rate by 80 basis points, and lowers stock prices by $13 \%$. The response of stock prices is therefore larger in both experiments. At the same time, the spillover effect to interest rates and to the other long-lived asset price is larger in response to a change in the expected housing return.

Table $3 \mathrm{~A}$ also shows what happens when the supply of long-lived assets drops by $5 \%$. For stocks, the experiment in row 4 reduces the flow of new equity from zero, the 1995 value, to $-5 \%$. This 
corresponds to a phase of substantial repurchases of stocks by corporations, such as that observed in the 1980s, or alternatively to a period where foreigners buy equity from domestic households. For houses, the experiment in row 5 reduces housing investment from its 1995 value of $4 \%$ to $-1 \%$. In both cases, stock and house prices both rise, while the nominal interest rate falls. The housing experiment leads to larger changes in the wealth-GDP ratio as well as larger spillover effects to the credit market and the respective other long-lived asset market. However, the relative change in the house price is now larger in both experiments.

Table 3A: Counterfactuals, 1995 distribution

experiment

(1) baseline

(2) stock exp. $+1 \%$

(3) house exp. $+1 \%$

(4) stock supply $-5 \%$

(5) house supply $-5 \%$

wealth/ portfolio weights
GDP bonds housing stocks

lend./ borr/

GDP GDP $\begin{array}{cc}\text { PD ratios } & \text { interest rate } \\ \text { housing stocks } & \text { nominal }\end{array}$

20.8

22.7

.061$$
2.54
$$

.15

.60

.25

.70

.31

.31

20.1

26.2

$22.1 \quad 19.2$

2.50

.15

.64

$.21 \quad 71$

.32

.41

25.3

27.1

31.8
.25

.85

.47

29.8

\footnotetext{
NotE: The first row reports 1995 baseline results for aggregate portfolio weights on bonds, housing and stocks, gross borrowing and lending as defined in Section A., the wealth-to-GDP ratio, the price-dividend ratios for housing and stocks together with the nominal 6-year interest rate. The remaining rows report counterfactuals described in the text.
}

The key effect of a reduction in asset supply is that "savings vehicles" that allow the household sector to transfer resources to the future become more scarce. As a result, all savings vehicles become more valuable - asset prices rise (as expected from (8)) while the interest rate falls. The drop in the interest rate goes along with an increase in gross borrowing by households: households themselves thus replace some of the supply of savings vehicles withdrawn by the rest of the economy. Compared to the common increase in prices, the relative change in prices and the associated portfolio shift both favoring the asset that has become more scarce - are somewhat smaller. The effects of a change in supply thus work through the consumption-savings margin more than through the portfolio choice margin. 


\section{Comparing equity and real estate}

We now consider the different responses of housing and equity markets to the above experiments. In our model, housing differs from equity because the overall scale of the housing market is bigger, its endowment distribution is less concentrated, the mean and volatility of its return are lower and it can be used as collateral. To isolate the role of housing as collateral, Table 3B repeats the counterfactuals of Table 3A with artificial data. In particular, the asset "equity" is now an artificial asset that has all the properties of housing in the data (that is, the same dividend, endowment distribution and return moments), but that cannot be used as collateral.

The baseline results in row 1 isolate the value of the collateral property: the true housing asset is about $10 \%$ more valuable than the artificial non-collateralizable housing asset. While this number comes from a different economy than the results in Table $3 \mathrm{~A}$ and hence does not capture the actual value of the collateral property of the US housing stock, we can conclude from this exercise that the collateral property is not a negligible component of the value of housing. The expected return experiments in rows 2 and 3 now give rise to essentially symmetric portfolio shifts and percentage price changes. Collateral is therefore not responsible for the stronger price response of equity discussed above. However, the interest rate effects are of a similar magnitude as in Table 3A.

The role of housing as collateral is thus at least in part responsible for the stronger spillover effects from housing to the credit market. Intuitively, if the expected return on either long-lived asset increases, the interest rate must also increase, so that the aggregate household sector - which is a net lender - continues to hold the outstanding bond supply. An increase in the expected housing return is special because it not only lowers the demand for bonds by net lenders, but also increases the supply of bonds (that is, mortgages) by net borrowers, as the collateral constraint permits more borrowing. Since the interest rate must rise not only to stimulate bond demand, but also to curb supply, it rises by more than when the expected stock return rises.

The stronger response of stock prices to expected return changes in Table $3 \mathrm{~A}$ is due to two properties of the model. The first, discussed above, is that a change in the return on one of the assets works mostly through the portfolio choice margin, and leaves total savings almost unchanged. Since the resources raised by the ROE in the credit market are given, this means that the equilibrium portfolio weight on bonds must also remain almost unchanged, and any increase in the weight on 
stocks, say, must be almost exactly offset by a decrease in the weight on houses. The second property is that the stock market is smaller than the housing market. It follows that an equal shift in weights must entail a proportionately larger change than in the value of stocks, and hence in the pricedividend ratio on stocks. In the artificial economy, where the scale of the two markets is the same, this effect vanishes.

\section{Table 3B: Counterfactuals, Artificial Data}

experiment

(1) baseline

(2) stock exp. $+1 \%$

(3) house exp. $+1 \%$

(4) stock supply $-5 \%$

(5) house supply $-5 \%$

(5) hetero infl exp

wealth/ portfolio weights
GDP bonds housing stocks

lend./ borr/

GDP

GDP

PD ratios housing stocks

interest rate nominal

2.54 .15 .45 .40 .63 .24 21.6 20.2 .054

2.55

.15

.38

.47

.60

.21

19.4

22.6

.057

2.55

.15

.52

.33

.65

.26

24.1

17.8

.060

2.99

.13

.45

.42

$.64 \quad .25$

24.7

29.1

.052

3.39

.11

.43

$.68 \quad .29$

27.5

21.0

.049

3.39

.15

.47

.38

.79

.40

22.4

19.2

.049

\section{Aggregation}

The distribution of household characteristics - in particular age and endowments - affects asset prices via the average savings rate (cf. (8), for example) as well as via average portfolio weights. Since households have homothetic preferences, it is not obvious that features of the distribution other than the means matter for prices. ${ }^{8}$ Recent work on calibrated incomplete markets models has derived "approximate aggregation" results: moments of the wealth distribution beyond the mean often have little effect on equilibrium asset prices (see Krusell and Smith 2006 for a survey).

Approximate aggregation obtains if individual savings $S(\bar{w}(i) / \hat{y}(i) ; i, q) \bar{w}$, viewed as a function of initial wealth $\bar{w}$, are well approximated by affine functions with a common slope:

$$
S(\bar{w}(i) / \hat{y}(i) ; i, q) \bar{w} \approx a(i, q, \hat{y}(i))+b(q) \bar{w}
$$

\footnotetext{
${ }^{8}$ In a standard general equilibrium model with identical homothetic preferences, the wealth distribution is irrelevant for prices: homotheticity leads to demand functions that are linear in wealth; if preferences are also identical, the slopes are all the same and aggregate demand is linear in aggregate wealth.
} 
at least on the support of the wealth distribution. Here the key property is that $b$ does not depend on any individual characteristics $i$. Assuming equal supply of equity and houses as in (8): the total value of long lived assets is then

$$
p^{h}+p^{e}=\frac{\bar{a}+b E-D}{1+f-b},
$$

where $\bar{a}$ is the population-weighted average of the intercepts $a$. The wealth-GDP ratio thus depends on the distribution of income only through the aggregate $E$.
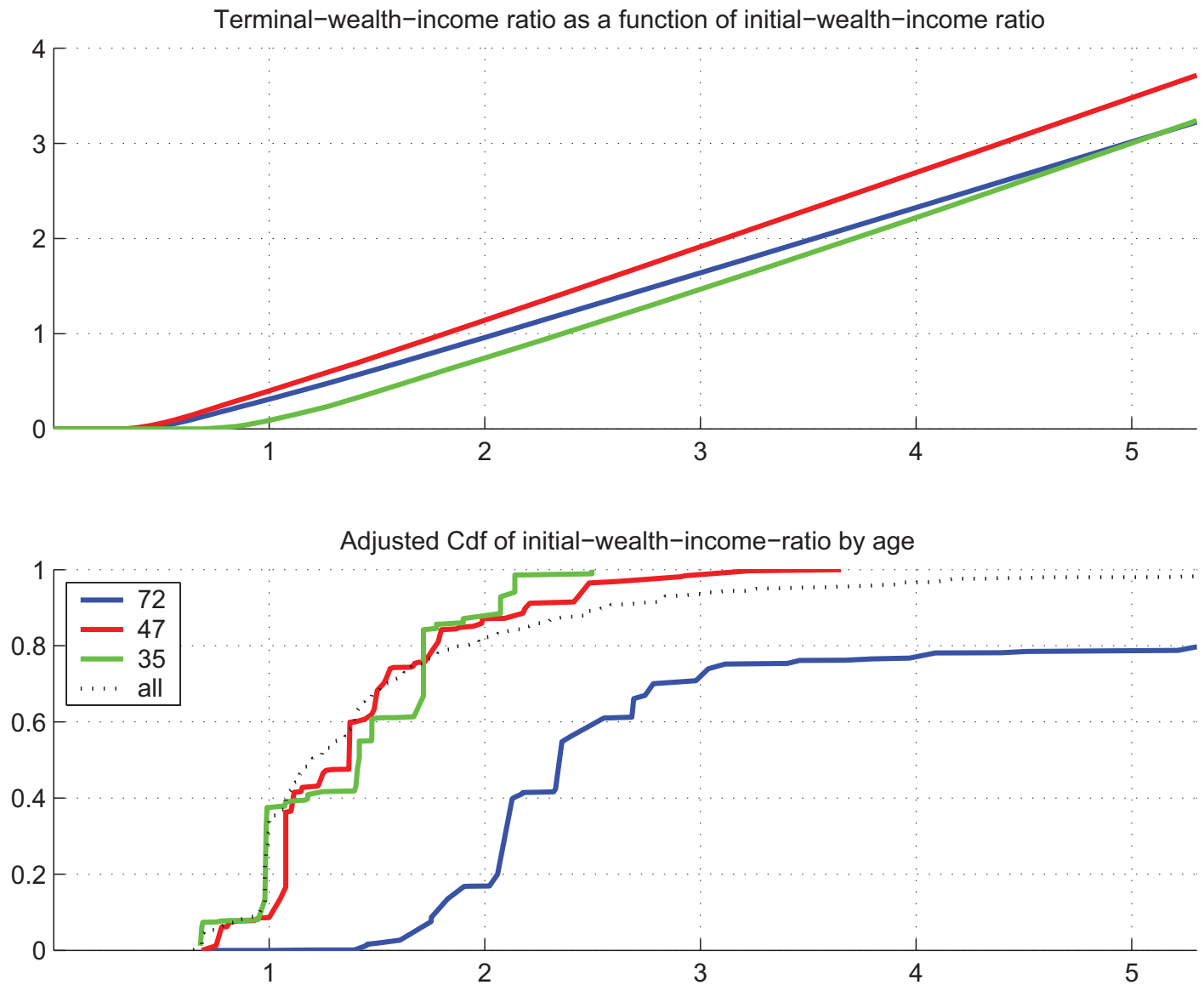

Figure 8: Aggregation Results

The top panel of Figure 8 plots the ratio of savings - or terminal wealth - to the permanent component of income $\hat{y}$ as a function of the wealth-to-income ratio $\bar{w} / \hat{y}$, for the same age groups as in Figure 6. Holding age fixed, savings are well approximated by an affine function in $\bar{w}$, if $\bar{w}$ is 
high relative to $\hat{y}{ }^{9}$ Moreover, the intercept is negative and proportional to $\hat{y}$ : rich households with a higher permanent component of income save less overall, but they save the same fraction of every additional unit of wealth. While approximate aggregation obtains for rich households within an age group, the savings function is not affine when $\bar{w}$ is low relative to $\hat{y}$. This is true especially for the youngest agents, for whom the nonnegativity constraint on savings is most relevant. In addition, the slopes differ by age, which suggests that the wealth distribution between cohorts matters for prices.

Our framework allows to assess how much heterogeneity in wealth matters for prices by comparing the measured wealth distribution to the model implied savings function. The bottom panel of Figure 8 plots a cumulative distribution functions for the wealth-to-income ratio $\bar{w} / \hat{y}$ by age. For easier interpretation, the cdf was adjusted so that integrating the savings functions for some age group in the top panel against the density derived from the corresponding cdf in the bottom panel yields aggregate savings (up to a scaling factor). ${ }^{10}$ Approximate aggregation within an age group thus obtains if most of the mass is in a region where the savings function is linear. While this is true for old and middle aged households who tend to have a lot of wealth relative to income, the majority of young agents (29-35) is in a region where the savings function is still convex.

\section{Supply, Demographics and Asset Prices 1968-95}

Panels A and B of Table 4 compare the baseline model to the data not only for 1995, but also for 1968 and 1978. For 1968, the baseline model captures the fact that the wealth-GDP ratio as well as the nominal interest rate were both slightly lower than their counterparts in 1995. It accounts for most of the difference because the variance of income shocks was lower in 1968, which implies that less precautionary savings lowers wealth and interest rates. The model captures only a small fraction of the portfolio shift towards housing that took place between 1968 and 1995. As a result, it cannot explain the observed increase in house prices, although it does produce a drop in the price dividend ratio on stocks.

With a spread of $2.75 \%$ between borrowing and lending rates, the model matches gross borrowing

\footnotetext{
${ }^{9}$ Comparison of Figures 6 and 8 shows that equal savings rates across individuals are sufficient, but not necessary to obtain common slopes $b$ of the savings functions (9).

${ }^{10}$ More specifically, each households' weight was multiplied by the ratio of its individual $\hat{y}(i)$ to the aggregate $\hat{y}(i)$.
} 
and lending in 1968. A fairly small drop in the spread - 75 basis points - is thus sufficient to account for the increase in the volume of credit. Changing the spread has otherwise little effect on the equilibrium. This is illustrated in Table 5, where we collect a set of counterfactuals designed to provide intuition for the baseline results in Table 4. The second row of Table 5 recomputes the equilibrium for 1968 with a spread of $2 \%$.

Household portfolios in 1978 were very different from those in 1968 or 1978: wealth as a percent of GDP was much smaller, and there was a strong portfolio shift from stocks into houses. The model with baseline expectations held fixed delivers the first fact, but not the second. The wealth to GDP ratio drops to about twice GDP in both the model and the data. However, the portfolio allocation in the model remains essentially the same as in 1995. As a result, the price dividend ratios of houses falls and that of houses rises, in contrast to what happened in the data.

Table 4: Baseline Results

\begin{tabular}{|c|c|c|c|c|c|c|c|c|c|c|}
\hline \multirow[t]{2}{*}{ year } & \multirow[t]{2}{*}{ beliefs } & \multirow{2}{*}{$\begin{array}{c}\text { wealth/ } \\
\text { GDP }\end{array}$} & \multicolumn{3}{|c|}{ portfolio weights } & \multirow{2}{*}{$\begin{array}{l}\text { lend./ } \\
\text { GDP }\end{array}$} & \multirow{2}{*}{$\begin{array}{l}\text { borr/ } \\
\text { GDP }\end{array}$} & \multicolumn{2}{|c|}{$\mathrm{PD}$ ratios } & \multirow{2}{*}{$\begin{array}{c}\text { interest rate } \\
\text { nominal }\end{array}$} \\
\hline & & & bonds & housing & stocks & & & housing & stocks & \\
\hline \multicolumn{11}{|c|}{ PANEL A: DATA } \\
\hline 1968 & & 2.41 & .17 & .51 & .32 & .61 & .20 & 20.1 & 32.3 & .057 \\
\hline 1978 & & 2.08 & .16 & .68 & .17 & .56 & .23 & 24.4 & 18.6 & .084 \\
\hline 1995 & & 2.51 & .15 & .59 & .26 & .70 & .31 & 20.4 & 23.9 & .061 \\
\hline \multicolumn{11}{|c|}{ Panel B: Model } \\
\hline 1968 & baseline & 2.44 & .16 & .59 & .25 & .60 & .19 & 23.6 & 24.8 & .059 \\
\hline 1978 & baseline & 2.11 & .16 & .59 & .25 & .53 & .20 & 21.9 & 28.5 & .062 \\
\hline 1995 & baseline & 2.51 & .15 & .60 & .25 & .70 & .31 & 20.8 & 22.7 & .061 \\
\hline
\end{tabular}

Note: Panel A reports the aggregate portfolio weights on bonds, housing and stocks from Figure 2; the gross borrowing and lending numbers from Section the SCF of 1962, the constructed numbers for 1978 and the SCF of 1995; the wealth-to-GDP ratio from Figure 1; the price-dividend ratios for housing and stocks together with the nominal 6year interest rate. Panel B reports the results computed from the model with baseline beliefs.

Three changes in fundamentals are important for the drop in the wealth-to-GDP ratio in 1978. The first is the change in the distribution of endowments illustrated in Figure 5. The special feature 
of the 1978 endowment distribution is that a larger fraction of the funds available for investment resides with the very youngest and oldest cohorts. As shown in the last section, the model predicts that these cohorts have small savings rates, which leads to lower wealth-to-income ratios and pushes interest rates up. This effect is reinforced by the effects of low ex post real interest rates, which also reduce the ratio of initial wealth to income and hence savings. A counteracting force is the reduction in bond supply documented in Figure 4 which tends to lower interest rates and slightly raises the wealth-GDP ratio. Taken together, these effects produce relatively stable interest rates and a low wealth-GDP ratio.

Table 5 reports experiments that consider the role of each of these three factors in isolation, leaving the others fixed at their 1968 values. The experiment in row 3 (1978 bond supply) retains the whole 1968 distribution of households, and changes only the supply of new bonds to the 1978 value, a reduction of $25 \%$. Since the supply of bonds drops, this experiment is similar to the counterfactual experiments that reduce the house and stock supplies in Table 3A above.

TABle 5: Additional Experiments for 1968 And 1978

\begin{tabular}{|c|c|c|c|c|c|c|c|c|c|c|}
\hline \multirow[t]{2}{*}{ year } & \multirow[t]{2}{*}{ experiment } & \multirow{2}{*}{$\begin{array}{c}\text { wealth/ } \\
\text { GDP }\end{array}$} & \multicolumn{3}{|c|}{ portfolio weights } & \multirow{2}{*}{$\begin{array}{l}\text { lend./ } \\
\text { GDP }\end{array}$} & \multirow{2}{*}{$\begin{array}{l}\text { borr/ } \\
\text { GDP }\end{array}$} & \multicolumn{2}{|c|}{$\mathrm{PD}$ ratios } & \multirow{2}{*}{$\begin{array}{c}\text { int. rate } \\
\text { nom. }\end{array}$} \\
\hline & & & bonds & housing & stocks & & & housing & stocks & \\
\hline 1968 & (1) baseline & 2.44 & .16 & .59 & .25 & .60 & .19 & 23.6 & 24.8 & .059 \\
\hline 1968 & (2) spread $=2 \%$ & 2.44 & .16 & .60 & .24 & .66 & .25 & 23.8 & 24.4 & .063 \\
\hline 1968 & (3) 1978 bond supply & 2.52 & .13 & .62 & .25 & .57 & .24 & 25.5 & 26.4 & .056 \\
\hline 1968 & (4) 1978 bond endowm. & 2.32 & .18 & .58 & .24 & .58 & .17 & 22.0 & 23.4 & .061 \\
\hline 1978 & (5) baseline & 2.11 & .16 & .59 & .25 & .53 & .20 & 21.9 & 28.5 & .062 \\
\hline 1978 & (6) 1968 bond market & 2.18 & .15 & .60 & .25 & .55 & .22 & 22.9 & 29.3 & .060 \\
\hline
\end{tabular}

Note: The table reports model results for various years and counterfactuals.

The results are also similar: a reduction in the supply of any savings vehicle - here bonds raises the prices of all savings vehicles; it thus raises the wealth to GDP ratio and lowers the nominal interest rate. Lower nominal interest rates in turn lead to more borrowing within the household sector - borrowing households supply more bonds now, mitigating some of the shortfall of bond 
supply from the rest of the rest of the economy. Because of the collateral constraint, borrowing goes along with more investment in housing relative to stocks - house prices increase proportionately more than stock prices and there is a portfolio shift from bonds into housing.

The experiment in row 4 (1968 bond endowments) retains the 1968 bond supply as well as the 1968 distribution of income, house and stock endowments. However, it constructs bond endowments by updating bond holdings with an interest rate factor that is about $3 \%$ lower than the factor used in the 1968 baseline case. The new factor thus lowers the initial wealth of lenders and increases the initial wealth of borrowers; its value is selected to make aggregate payoffs on bonds as a percent of GDP as low as in 1978, where inflation significantly reduced the ex post real interest rate.

The effect of this experiment is the opposite of a reduction in asset supply: a reduction in bond payoffs lowers initial wealth and thus reduces the demand for all savings vehicles and lowers all prices as well as the wealth-GDP ratio. The reason is that the household sector on aggregate is a net lender so that for the majority of households (in wealth-weighted terms) the wealth-income ratio and the savings rate go down. Of course, at the same time, borrower households experience an increase in their wealth-income ratio, so that the distribution of wealth-income ratios becomes less dispersed. This explains the drop in gross credit volume from the experiment.

Line 6 (1968 bond market) uses the 1978 distribution, but fixes the bond supply at its 1968 value. In addition, it increases the bond endowments by raising the interest rate factor by about $3 \%$, so that the aggregate bond endowments is also at the higher 1968 value. This is a way to isolate the effect of the income and endowment distribution from the other two factors. The result is a drop in the wealth-GDP ratio that is twice as large as the drop caused by lower bond endowments alone. It is driven by the lower savings rates of the 1978 population.

\section{The Effects of Inflation}

In this section, we consider the effects of inflation on the price-dividend ratios of real assets in the 1970s. We use our model to quantify the extent to which changes in $(i)$ expected inflation, (ii) inflation uncertainty and (iii) lower stock returns predicted by high expected inflation contribute to higher house prices and lower stock prices. We also consider the implications of lower expectations 
about real growth. To compare different expectation scenarios, we not only look at stock and house prices, but also at the nominal interest rate, the volume of credit, the overall ratio of wealth to GDP and household portfolio weights. The relevant statistics are reported in Table 6. Rows 1 and 2 simply repeat the Table 4 statistics from the data and the results based on baseline beliefs, respectively.

\section{Expected Inflation and Taxes}

Row 3 of Table 6 focus on the effects of higher expected inflation. Row 3, labelled "hi inflation expectations" increases expected inflation for all households from the baseline number of $4 \%$ to the median 5-year inflation forecast from the Michigan survey, averaged over the trading period, which is $6.3 \%$. In this experiment, all effects of expected inflation are due to nominal rigidities in the tax system. In particular, taxation of nominal returns makes housing more attractive as an investment relative to stocks and bonds, and it encourages mortgage borrowing.

To see the effect of expected inflation on real after tax returns, let $r_{t}^{e}$ denote the pretax real return on equity and let $\pi_{t}$ denote the inflation rate. Under our assumption of a single effective tax rate on nominal equity returns, the after-tax real return on equity is $(1-\tau) r_{t}^{e}-\tau \pi_{t}$. The expected after-tax real return on equity is thus decreasing in expected inflation. In contrast, we have assumed that housing returns are not taxed, so that the expected real return on housing does not depend on expected inflation. As expected inflation increases, real estate thus become more attractive relative to equity. The return on nominal bonds is $(1-\tau) i_{t}-\pi_{t}=(1-\tau) r_{t}^{b}-\tau \pi_{t}$, where $i_{t}$ is the nominal interest rate and $r_{t}^{b}=i_{t}-\pi_{t}$ is the pretax real return. Given a nominal rate, holding bonds thus also becomes less attractive as expected inflation increases, whereas mortgage borrowing becomes more attractive because interest is tax deductible.

Compared to the baseline, higher expected inflation leads to a drop in the price-dividend ratio on stocks and an increase in the price-dividend ratio on houses. At the same time, the nominal interest rate increases by more than the increase in expected inflation. Both results follow directly from the increased tax burdens on stocks and bonds. On the one hand, the taxation of nominal equity returns works like a change in expected stock returns, already discussed in Section VI: a drop in the expected return on stocks does not change the wealth-GDP ratio or interest rate much, but lowers the price of stocks. On the other hand, the taxation of nominal interest induces an inflation premium on top of the increase in the nominal rate warranted by the Fisher equation. 
Quantitatively, the changes in household portfolios shown in row 3 do not come close to matching the portfolio shift of the 1970s shown in row 1. At the same time, the resulting nominal interest rate of $9 \%$ is more than half a percentage point higher than the observed rate of $8.4 \%$. Our calculations are based on a tax rate of $20 \%$, which is consistent with the numbers reported by Sialm (2006) for average effective tax rates on equity returns as well as capital gains tax rates in the 1970s. It is still interesting to ask what happens for higher tax rates. To match the portfolio weights exactly requires a tax rate of $45 \%$. However, the resulting increase in the inflation premium pushes the nominal interest rate up to $10.7 \%$, and the overall lower after tax return on wealth lowers the wealth-GDP ratio to 2.02. This reveals a basic tension between tax effects on long-lived assets and the credit market. We conclude that the effects of expected inflation through taxes cannot be the only factor behind the 1970s portfolio shift.

\section{Expected Inflation and Disagreement}

According to the Michigan Survey, households disagreed about expected inflation in the 1970s. Interestingly, disagreement is related to age in a systematic way. Figure 9 plots population median forecasts since 1979 together with median forecasts for the youngest and oldest cohorts in the Michigan survey. During the high inflation years in the late 1970s and early 1980s, older households expected much lower inflation than younger households; the discrepancy vanished as inflation subsided in the 1990s. Our model offers a natural laboratory for studying the impact of heterogeneity in expectations by age. The exercise in row 4 of Table 6 , labelled "heterogeneous inflation expectations", assumes that the inflation rate expected by an age cohort in the model is equal to the corresponding cohort median in the Michigan Survey.

Heterogeneity in inflation expectations introduces disagreement about real rates - a second mechanism that pushes house prices up and stock prices down. This disagreement stimulates borrowing and lending among households and drives up the (relative) price of collateral, that is, houses. Indeed, given a nominal interest rate quoted in the credit market, young households (who expect high inflation) perceive a lower real interest rate than old households (who expect low inflation). This generates gains from trade: young households believe that borrowing is a bargain and borrow from old households, who are happy to lend. Since any borrowing requires collateral, more credit created within the household sector leads to a stronger demand for housing, which drives up house 


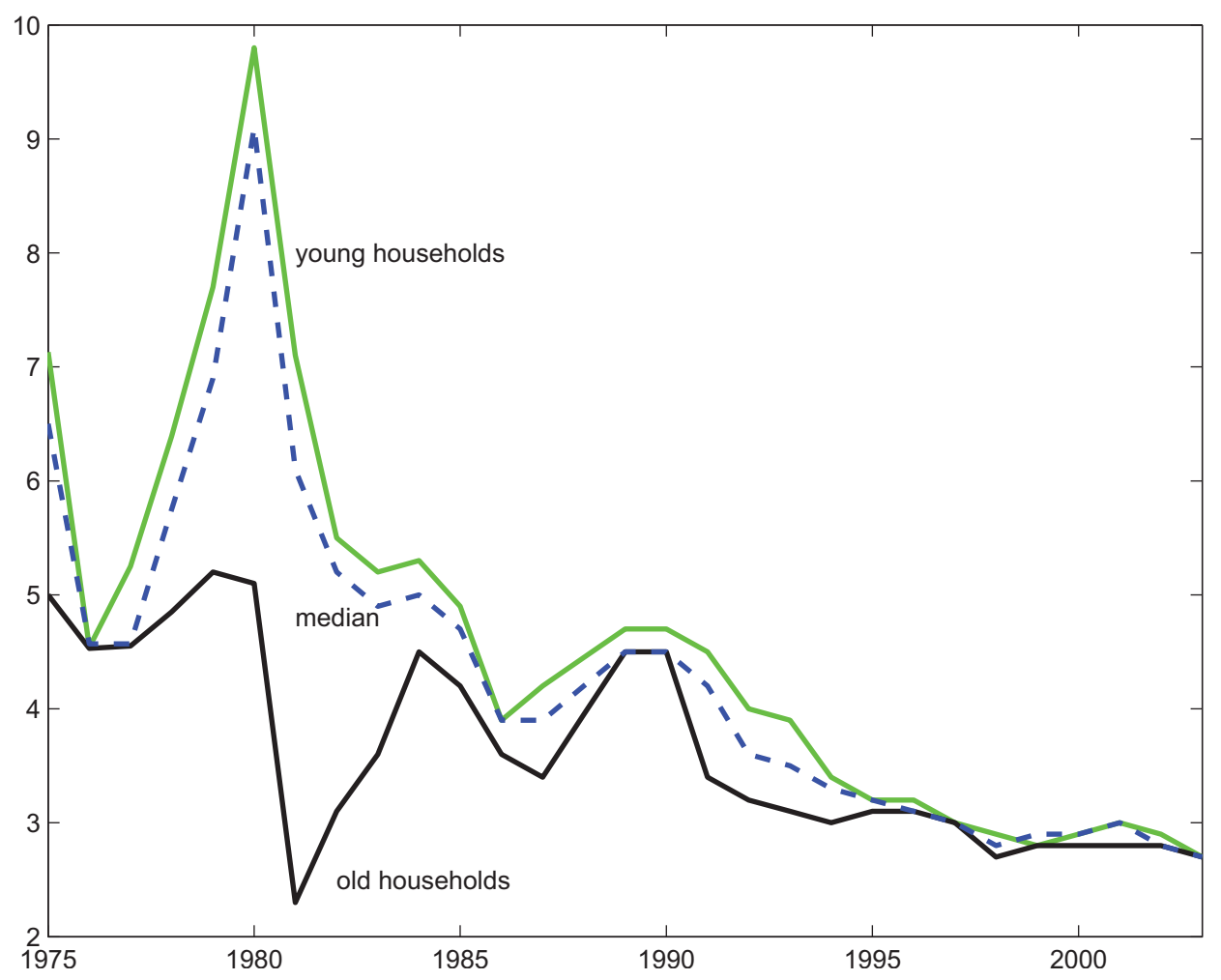

Figure 9: Median inflation expectations over the next 5 years, Michigan Survey of Consumers. The lines with "young households" and "old households" represent expecations by the youngest (18-34 years) and oldest (above 65 years) cohorts in the Michigan survey. These lines provide bounds for the expectations by other cohorts (not shown in the picture), which are monotonic in age.

prices. At the same time, both borrowers and lenders lower their demand for stocks: the former prefer houses, while the latter prefer bonds. As a result, the stock price falls.

Quantitatively, a switch from the baseline to survey expectations explains half the observed portfolio shift from the baseline $59 \%$ portfolio weight on housing to the observed $68 \%$. Compared with (homogeneous) "hi inflation expectations," the (heterogeneous) survey expectations generate double the portfolio shift, without changing our previous conclusions about the nominal interest rate and wealth-GDP ratio. The survey expectations also lead to an increase in borrowing and lending. While any disagreement about real rates leads to gains from trade, the basic effect is reinforced in our context because inflation expectations are correlated with households' propensity to borrow: as discussed in Section 7, younger households tend to have lower wealth relative to permanent income and leverage up more. 


\section{Inflation Uncertainty}

The "hi inflation volatility" experiment reported in row 5 of Table 6 doubles the conditional volatility of inflation, from $3 \%$ to $6 \%$ p.a. It is motivated by the increase in uncertainty about inflation. In our model, higher conditional volatility of inflation increases the conditional volatility of real bond returns and the ex post real cost of mortgage financing. The main difference to the baseline results is that there is now less nominal borrowing and lending within the household sector and a higher nominal interest rate. The lower volume of credit is natural as nominal instruments have become less attractive to both borrowers and lenders. The nominal interest rate increases because the household sector as a whole is a net lender and must be compensated if it is to hold the nominal debt of the rest of the economy.

Increasing inflation volatility has little effect on the overall wealth-GDP ratio. Indeed, it is a comparative static that affects the returns on one asset, leaving those on other assets unchanged. As is the case for other experiments of this type, the overall return on wealth and the savings decision are not affected much and the equilibrium wealth-GDP ratio stays essentially the same. Aggregate portfolio weights also remain unchanged. On the one hand, households are required to hold the same value of bonds issued by the rest of the economy in equilibrium, so that the portfolio weight on bonds remains unchanged if the wealth-GDP does not change. On the other hand, the effect of a change in the relative volatility of after tax returns on stocks and houses is quantitatively small so that the weights on stocks and houses also move little.

\section{Lower Stock Return and Growth Expectations}

In rows $6-8$ of Table 6 , we consider experiments that increase pessimism about various parts of the U.S. economy. Row 6 considers lower expected stock returns, row 7 assumes lower growth in the aggregate component of non-asset income, and row 8 assumes lower returns on both long-lived assets together with low non-asset income growth. The latter case can be viewed as capturing pessimism about the economy as a whole, which shows up in lower expectations of both dividends and nonasset income. Within our framework, it does not matter where lower return expectations come from. One source of pessimism in the 1970s was an expected slowdown in productivity. Another was low projections of corporate profits due to higher inflation. Inflation thus motivates an experiment in which stock return expectations are lower, while expected payoffs on human capital and housing 
remain unchanged.

To get an idea about the plausible order of magnitude for pessimism induced by inflation, we use the study of Fama and Schwert (1977), who document that measures of expected inflation are significant predictors of stock returns. The regression results in their Table 6 represent real-time forecasts of returns on a variety of assets - stocks, housing, and bonds - based on data available at that time. Their results indicate that a one percentage-point increase in expected inflation lowers the forecast of real stock returns by roughly 6 percentage points over the following year, but leaves the forecasts of real housing returns unchanged. Assuming that today's inflation forecasts do not predict stock returns beyond the next year, the 1.5 percentage point increase in expected inflation measured by the Michigan Survey would lower expected real stock returns over the next 6 years by roughly 1.5 percentage points.

Row 6 of Table 6 reports results for stock return expectations that are 1.5 percentage points lower than the historical mean. Since this experiment also changes the returns on only one asset, it does not affect strongly the savings decision and the wealth-GDP ratio moves little. However, as households lower their return expectations for stocks, other assets become relatively more attractive and thus valuable. As in the counterfactual experiments in Table 3A, the price-dividend ratios of stocks and housing are highly sensitive to households' subjective equity return; in particular, the stock market falls by $25 \%$. The interest rate falls, although the effect is not large. This scenario is able to generate large movements in the price of real assets together with a drop in the interest rate.

Row 8 of Table 6 shows that the situation is different if pessimism affects not only the corporate sector, but also labor income and the dividends on housing. Relative to the baseline, a 1\% drop in expected growth induces a significant increase in the wealth-GDP ratio (about 10\%) together with a large drop in the interest rate, by 1.3 percentage points. Two effects combine to generate this result. First, a drop in expected non-asset income lowers the permanent component of non-asset income which increases the savings rates of all households and drives up the prices of the long-lived assets. This effect is also relevant when dividends are not affected at all: row 7 shows an increase in the wealth-GDP ratio when only non-asset income growth is expected to be lower. Second, the interest rate must fall to lower the return on bonds and bring it back in line with the lower expected return on stocks and houses. In equilibrium, the portfolio weights then remain unchanged, since the 
experiment has not changed the relative returns on stocks and houses much.

TABle 6: The Effects of Inflation

\begin{tabular}{|c|c|c|c|c|c|c|c|c|c|}
\hline \multirow[b]{2}{*}{ beliefs } & \multirow{2}{*}{$\begin{array}{c}\text { wealth/ } \\
\text { GDP }\end{array}$} & \multicolumn{3}{|c|}{ portfolio weights } & \multirow{2}{*}{$\begin{array}{l}\text { lend./ } \\
\text { GDP }\end{array}$} & \multirow{2}{*}{$\begin{array}{l}\text { borr./ } \\
\text { GDP }\end{array}$} & \multicolumn{2}{|c|}{ PD ratios } & \multirow{2}{*}{$\begin{array}{l}\text { nominal } \\
\text { int. rate }\end{array}$} \\
\hline & & bonds & housing & stocks & & & housing & stocks & \\
\hline (1) -1978 data - & 2.08 & .16 & .68 & .16 & .56 & .23 & 24.4 & 18.6 & .084 \\
\hline (2) baseline & 2.11 & .16 & .59 & .25 & .53 & .20 & 21.9 & 28.5 & .062 \\
\hline (3) hi infl exp & 2.09 & .16 & .61 & .23 & .53 & .20 & 22.2 & 25.8 & .090 \\
\hline (4) hetero infl exp & 2.09 & .16 & .63 & .21 & .68 & .35 & 22.8 & 24.3 & .089 \\
\hline (5) hi infl volatility & 2.11 & .16 & .59 & .25 & .51 & .18 & 21.9 & 27.9 & .066 \\
\hline (6) stock exp $-1.5 \%$ & 2.05 & .16 & .64 & .20 & .54 & .21 & 23.0 & 21.6 & .060 \\
\hline \multicolumn{10}{|l|}{ Lower expected growth } \\
\hline (7) labor $-1 \%$ & 2.27 & .15 & .60 & .25 & .57 & .24 & 23.9 & 30.8 & .060 \\
\hline (8) $\ldots \&$ returns $-1 \%$ & 2.25 & .15 & .59 & .26 & .56 & .23 & 23.1 & 31.6 & .049 \\
\hline $\begin{array}{l}\text { Combination } \\
\text { (9) }\end{array}$ & 2.13 & .16 & .68 & .16 & .56 & .23 & 24.9 & 19.0 & .084 \\
\hline
\end{tabular}

Note: Rows 1 and 2 repeat the results with baseline expectations from Table 3. The other scenarios change expectations over the next six years away from the baseline. Row 3 ("hi inflation expectations") increases households' expected inflation from the baseline $4 \%$ to the median $6.3 \%$ in the Michigan Survey of Consumers, averaged over 1975-1980. Row 4 ("heterogeneous inflation expectations") sets every age cohort's expected inflation in the model equal to the cohort median in the Michigan Survey, averaged over 1975-80. Row 5 ("high inflation volatility") doubles the conditional volatility of inflation. Row 6 lowers expected pretax stock returns by $1.5 \%$. Row 7 lowers the expected growth rate of non-asset income by $1 \%$. Row 8 lowers the expected growth rate of non-asset income as well as expected pretax house and stock returns by 1\%. Row 9 combines expected cohort inflation rates (as in row 4), lower expected growth rates of non-asset income and expected house returns by $.88 \%$, lower pretax expected stock returns by $2.6 \%$, and multiplies the conditional volatility of inflation by a factor of 4 .

\section{Combining Expectations of High Inflation and Low Growth}

The discussion so far suggests that neither higher and more uncertain inflation expectations nor lower growth expectations can by themselves account for the experience of the 1970s. Under survey inflation expectations and baseline inflation uncertainty, there is some portfolio shift towards housing, but the volume of credit and the interest rate are higher than in the data. Inflation uncertainty 
reduces the volume of credit, but pushes the interest rate even higher. Lower expected growth only leads to a portfolio shift if pessimism is restricted to the corporate sector. Otherwise its main effect is to offset the wealth dip that the model generates at baseline beliefs and to lower the interest rate.

It is natural to ask whether a combination of the above effects can provide a plausible account of the 1970s. This question is addressed by the experiment in row 9 of Table 6 . It assumes that expected inflation comes from the Michigan survey cohort medians, but also that the conditional volatility of inflation is multiplied by 4 , that expected income growth and house returns drop by .9\% (relative to the baseline) and stock returns drop by $2.6 \%$. In other words, overall growth is expected to drop by close to $1 \%$, while stock returns are expected to drop by an additional $1.7 \%$, about the amount motivated above by the role of expected inflation as a predictor of returns. The results show that all portfolio moments and the interest rate are matched exactly, while the wealth-GDP ratio is still very close to the benchmark and hence also to its value in the data.

Our combination experiment suggests a story according to which asset prices and household positions in the 1970s were driven by two forces. First, there were three channels through which changes in inflation expectations drove the portfolio shift: a little more than half of the shift was due to the fact that higher expected inflation predicts lower stock returns, while about one quarter each was due to disagreement about real interest rates and nominal rigidities in the tax code. Disagreement also accounted for the increase in credit volume, which would have been even stronger without the increase in inflation uncertainty. The second important force was lower expected growth. Here pessimism about labor income and pessimism about asset returns had offsetting effects on the wealthGDP ratio, which was mostly driven by demographics and the effects of surprise inflation (cf Section VII). At the same time, pessimism about asset returns put downward pressure on interest rates that partly offset the effects of expected inflation.

\section{Conclusion}

In this paper, we have combined aggregate data from the Flow of Funds with household-level data from successive SCF cross sections. This approach allows us to measure the income and asset endowment distribution across households at the beginning of each trading period. To capture structural 
change, we consider a sequence of temporary equilibria of this heterogeneous agent economy. There are three assets - housing, stocks and nominal bonds. There is no riskless asset, so that market are incomplete. During the 1970s, households anticipate higher inflation and view inflation as more uncertain. In particular, we document that young households adjusted their inflation forecasts more than old agents. These changes in inflation expectations make housing more attractive, because of capital gains taxes on stocks and mortgage deductibility. Moreover, agents interpret higher inflation expectations as bad news for future stock returns. Taken together, these effects can then explain the opposite movements of house and stock prices in the 1970s. 


\section{References}

Abel, Andrew B. 2003. "The Effects of a Baby Boom on Stock Price and Capital Accumulation in the Presence of Social Security." Econometrica 71(2), pp. 551-578.

Alvarez, Fernando and Urban Jermann 2001. "Quantitative Asset Pricing Implications of Endogenous Solvency Constraints." Review of Financial Studies 14(4), pp. 117-151.

Antoniewicz, Rochelle 2004. "A Comparison of the Household Sector from the Flow of Funds Accounts and the Survey of Consumer Finances." Working Paper, Federal Reserve Board of Governors.

Barsky, Robert B. 1989. "Why Don't the Prices of Stocks and Bonds Move Together?" American Economic Review 79(5), pp. 1132-1145.

Brav, Alon, George M. Constantinides and Christopher C. Geczy 2002. "Asset Pricing with Heterogeneous Consumers and Limited Participation: Empirical Evidence." Journal of Political Economy 110, pp. 793-824.

Campbell, Jeffrey R. and Zvi Hercowitz 2005. "The Role of Collateralized Household Debt in Macroeconomic Stability." Working paper 11330, NBER.

Campbell, John Y. and Joao F. Cocco 2003. "Household Risk Management and Optimal Mortgage Choice." Quarterly Journal of Economics 118, pp. 1449-1494.

Caplin, Andrew, Sewin Chan, Charles Freeman, and Joseph Tracy 1997. Housing Partnerships. Cambridge and London: MIT Press.

Chambers, Matthew, Carlos Garriga and Don E. Schlagenhauf 2006. "Accounting for Changes in the Homeownership Rate." Working Paper, University of Florida.

Cocco, Joao F. 2005. "Portfolio Choice in the Presence of Housing." Review of Financial Studies 18, pp. 535-567.

Constantinides, George M., John B. Donaldson and Rajnish Mehra 2002. "Junior Can't Borrow: A New Perspective on the Equity Premium Puzzle." Quarterly Journal of Economics 117, pp. 269-296.

Constantinides, George M. and Darrell Duffie 1996. "Asset Pricing with Heterogeneous Consumers." Journal of Political Economy 104(2), pp. 219-40.

Doepke, Matthias and Martin Schneider 2006. "The Real Effects of Inflation through the Redistribution of Nominal Wealth." Working paper, UCLA and NYU.

Epstein, Larry G. and Stanley E. Zin 1989. "Substitution, Risk Aversion, and the Temporal Behavior of Consumption and Asset Returns: A Theoretical Framework." Econometrica 57, pp. 937-969.

Fama, Eugene F. and G. William Schwert 1977. "Asset Returns and Inflation." Journal of Financial Economics 5(2), pp. 115-146.

Feldstein, Martin 1980. "Inflation and the Stock Market." American Economic Review 70(5), pp. 839-847. 
Fernandez-Villaverde, Jesus and Dirk Krueger 2005. "Consumption and Saving over the Life Cycle: How Important Are Consumer Durables?" Working Paper, Penn.

Flavin, Marjorie and Takashi Yamashita 2002. "Owner-Occupied Housing and the Composition of the Household Portfolio." American Economic Review 92(1), pp. 345-362.

Geanakoplos, John, Michael Magill, and Martine Quinzii 2004. "Demography and the Long-run Predictability of the Stock Market." Brookings Papers on Economic Activity 1, pp. 241-307.

Gomes, Francisco and Alex Michaelides 2005. "Optimal Life-Cycle Asset Allocation: Understanding the Empirical Evidence." Journal of Finance 60(2), pp. 869-904.

Gourinchas, Pierre-Olivier and Jonathan Parker 2002. "Consumption over the Life Cycle." Econometrica 70 , pp. 47-89.

Grandmont, Jean-Michel 1977. "Temporary General Equilibrium." Econometrica 45, pp. 535-572.

Grandmont, Jean-Michel 1982. "Temporary General Equilibrium Theory." Chapter 19 in K.J. Arrow and M.D. Intriligator, Eds, Handbook of Mathematical Economics, North Holland, Amsterdam.

Heathcote, Jonathan, Kjetil Storesletten and Giovanni L. Violante 2004. "The Macroeconomic Implications of Rising Wage Inequality in the United States." Working paper, NYU.

Heaton, John and Deborah J. Lucas 1996. "Evaluating the Effects of Incomplete Markets on Risk Sharing and Asset Pricing." Journal of Political Economy 104, pp. 443-487.

Heaton, John and Deborah J. Lucas 2000. "Portfolio Choice and Asset Prices: The Importance of Entrepreneurial Risk." Journal of Finance 55, pp. 1163-1198.

Hubbard, R. Glenn, Jonathan Skinner, and Stephen P. Zeldes 1994. "The Importance of Precautionary Motives in Explaining Individual and Aggregate Saving." Carnegie-Rochester Conference Series on Public Policy 40, pp. 59-125.

Jagannathan, Ravi and Narayana Kocherlakota 1996. "Why Should Older People Invest Less in Stocks Than Younger People?" Federal Reserve Bank of Minneapolis Quarterly Review 20(3), pp. 11-23.

Kocherlakota, Narayana and Luigi Pistaferri 2005. "Asset Pricing Implications of Pareto Optimality with Private Information." Working paper, University of Minnesota and Stanford.

Krusell, Per and Anthony Smith 1998. "Income and Wealth Heterogeneity in the Macroeconomy." Journal of Political Economy 106(5), pp. 867-896.

Krusell, Per and Anthony Smith 2006. "Quantitative Macroeconomic Models with Heterogeneous Agents." Working paper, Princeton and Yale.

Lustig, Hanno and Stijn van Niewerburgh 2005. "Housing Collateral, Consumption Insurance and Risk Premia." Working paper, UCLA and NYU.

Mankiw, Gregory N. and David Weil 1989. "The Baby Boom, the Baby Bust and the Housing Market." Regional Science and Urban Economics 19, pp. 235-258. 
McGrattan, Ellen R. and Edward C. Prescott 2005. "Taxes, Regulations, and the Value of U.S. and U.K. Corporations." Review of Economic Studies 72(3), pp. 767-797.

Nakajima, Makoto 2005. "Rising Earnings Instability, Portfolio Choice, and Housing Prices." Working paper, University of Illinois.

Ortalo-Magne, Francois and Sven Rady 2006. "Housing Market Dynamics: On the Contribution of Income Shocks and Credit Constraints." Review of Economic Studies 73(2), pp. 459-485.

Piazzesi, Monika, Martin Schneider and Selale Tuzel 2007. "Housing, Consumption and Asset Pricing." Journal of Financial Economics 83(3), pp. 531-569.

Poterba, James 1991. "House Price Dynamics: The Role of Tax Policy and Demographics." Brookings Papers on Economic Activity 2, pp. 143-203.

Sialm, Clemens 2006. "Tax Changes and Asset Pricing: Time-Series Evidence." Working Paper, University of Michigan.

Storesletten, Kjetil, Chris I. Telmer, and Amir Yaron 2004. "Cyclical Dynamics in Idiosyncratic Labor-Market Risk." Journal of Political Economy 112, pp. 695-717.

Summers, Lawrence H. 1981. "Inflation, the Stock Market, and Owner-Occupied Housing." American Economic Review 71, pp. 429-434.

Yang, Fang 2006. "Consumption Along the Life Cycle: How Different Is Housing?" Working paper, University of Minnesota.

Yao, Rui and Harold Zhang 2005. "Optimal Portfolio Choice with Risky Housing and Borrowing Constraints." Review of Financial Studies 18, pp. 197-239.

Zeldes, Stephen P. (1989). "Optimal Consumption with Stochastic Income: Deviations from Certainty Equivalence." Quarterly Journal of Economics 104, pp. 275-298. 


\section{Appendix}

\section{A Assets and Income}

This appendix describes how we map observed asset classes into the three assets present in the model, and how we measure aggregate and household level asset holdings, as well as non-asset income.

\section{A. Data and Definitions}

We map the three assets in the model to three broad asset classes in US aggregate and household statistics. Our main data sources are the Flow of Funds Accounts (FFA) for aggregates and the Survey of Consumer Finances (SCF) for individual positions. To make these data sets comparable, we must ensure that aggregates match. As shown by Antoniewicz (2004), the match is good for most asset classes in both 1989 and 1995, after a few adjustments. However, our own computations show that the match for nominal assets is bad for the 1962 SCF. For some classes of assets, especially short-term deposits, the SCF aggregates are only about 50\% of the FFA aggregates. Apparent underreporting of short-term nominal assets is also present in later SCFs, but is less severe. To achieve a comparable time series of positions, we assume throughout that the FFA aggregates are correct and that individual positions in the SCF suffer from proportional measurement error. We then multiply each individual position by the ratio of the FFA aggregate and the SCF aggregate for the same asset class.

Asset classes

We identify equity with shares in corporations held and controlled by households, including both publicly traded and closely held shares, and both foreign and domestic equity. We also include shares held indirectly through investment intermediaries if the household can be assumed to control the asset allocation (into our broad asset classes). We take this to be true for mutual funds and defined contribution (DC) pensions plans. For these intermediaries, while the fund manager determines the precise composition of the portfolio, the household typically makes the decision about equity versus bonds by selecting the type of fund.

We thus consolidate mutual funds and DC pension funds. For example, when households own a 
mutual fund, an estimate of the part of the fund invested in stocks is added to stock holdings. In contrast, we do not include equity held in defined benefit (DB) pension plans, since the portfolios of these plans are not controlled by households themselves. Instead, DB plans are treated as a tax-transfer system sponsored by the rest of the economy (in practice, the corporate sector or the government). We also do not include noncorporate business, which is treated partly as real estate and partly as labor income, as described below.

We construct an annual series for the aggregate value of household sector equity holdings. Our starting point is the published series in the FFA. We cannot use that series directly, since it contains (i) the market value of the equity component of foreign direct investment (that is, equity positions by foreigners in excess of $10 \%$ of shares in a US corporation) and (ii) the market value of equity held by DB pension funds. We estimate the equity component of FDI using data on the International Investment Position from the Bureau of Economic Analysis. Shares held by defined benefit pension funds are available from the FFA. Our series is obtained by subtracting $(i)$ and $(i i)$ from the FFA series on household equity holdings.

We derive estimates of net new equity purchased by households using a similar correction of FFA numbers. Finally, our concept of dividends equals dividends received by households from the National Income and Product Accounts (NIPA) less dividends on their holdings in DB pension plans. We use the numbers on value, dividends and new issues to calculate price dividend ratios and holding returns on equity. The properties of the return series are discussed in Appendix B below. For household-level positions, we use the Survey of Consumer Finances, which also contains direct holdings of publiclytraded and closely-held shares, as well as an estimate of equity held indirectly through investment intermediaries.

Our concept of residential real estate contains owner-occupied housing, directly held residential investment real estate, as well as residential real estate recorded in the FFA/NIPA as held indirectly by households through noncorporate businesses. This concept contains almost all residential real estate holdings, since very few residential properties are owned by corporations. To construct holdings of tenant-occupied residential real-estate at the individual level, we start from the SCF numbers and then add a proportional share of the household's noncorporate business position. This share is selected so that our aggregate of tenant-occupied real estate over all households matches 
the corresponding value from the FFA. We take housing dividends to be housing consumption net of maintenance and property tax from NIPA. For net purchases of new houses, we use aggregate residential investment from NIPA. As with equity, the annual series for holdings, dividends and new issues give rise to a return series, discussed below.

Household bond holdings are set equal to the net nominal position, that is, the market value of all nominal assets minus the market value of nominal liabilities. Nominal assets again include indirect holdings through investment intermediaries. To calculate market value, we use the market value adjustment factors for nominal positions in the U.S. from Doepke and Schneider (2006). In line with our treatment of tenant-occupied real estate, we assign residential mortgages issued by noncorporate businesses directly to households. At the individual level, we assign a household mortgages in proportion to his noncorporate business position, again with a share selected to match the aggregate value of residential mortgages from the FFA.

\section{Non-Asset Income}

Our concept of non-asset income comprises all income that is available for consumption or investment, but not received from payoffs of one of our three assets. We start by constructing an aggregate measure of such income from NIPA. Of the various components of worker compensation, we include only wages and salaries, as well as employer contributions to DC pension plans. We do not include employer contributions to DB pension plans or health insurance, since these funds are not available for consumption or investment. However, we do include benefits disbursed from DB plans and health plans. Also included are transfers from the government. Finally, we subtract personal income tax on non-asset income.

Non-asset income also includes dividends from noncorporate business except those attributable to residential real estate. To construct the latter concept of noncorporate dividends, we use the aggregate price-dividend ratio of housing to estimate the housing dividend provided by an individual's private business. Our approach essentially splits up the noncorporate sector into a real estate component that is very capital intensive and relies heavily on debt finance, and a rest that is much more labor intensive. Indeed, the capital stock of the noncorporate nonfinancial sector in 1995 was $\$ 3.6$ trn, of which $\$ 2.4$ trn was residential real estate. 
Given the aggregate series of income, we apply the same conventions to individual income in the SCF to the extent possible. A problem is that the SCF does not report employer contributions to DC plans and only reports pretax income for all items. To address this issue, we apply a proportional tax rate to pretax non-asset income reported in the SCF, where the tax rate is chosen such that aggregate non-asset income is equal to its counterpart from NIPA. The outcome is an income distribution that matches with NIPA at the aggregate level.

\section{B. Measuring the Distribution of Endowments}

Consumers in our model are endowed with both assets and non-asset income. To capture decisions made by the cross-section of households, we thus have to initialize the model for every period $t$ with a joint distribution of asset endowment and income. We derive this distribution from asset holdings and income observed in the previous period $t-1$. Limits on data availability imply that we have to resort to different approaches for the different years. For 1995, the data situation is best, since we can use the SCF in the 4th year of period $t$ together with the SCF from the 4 th year of period $t-1$. We describe our strategy first for this case. We then explain how it is modified for earlier years where less data are available.

Approximating the distribution of households

In principle, one could use all the households in SCF and update them individually. This would lead to a large number of agents and consequently a large number of portfolio problems would have to be solved. We simplify by approximating the distribution of endowments and income with a small number of household types. First, we sort households into the same nine age groups described at the beginning of this section. Within each age group, we then select 6 subclasses of SCF households. We start by extracting the top $10 \%$ of households by net worth. Among the bottom $90 \%$ net worth, we divide by homeowner and renter. We then divide homeowners further into "borrowers" and "lenders." Here a household is a borrower if his net nominal position - nominal asset minus nominal liabilities - is negative. We further subdivide each homeowner category into high/low wealth-to-income ratios.

The above procedure splits up households into $9 \times 6=54$ different cells. We assume that all households that fall into the same cell are identical and compute asset positions at the cell level. The SCF survey weights determine the cell population. Naturally, the procedure loses some features of 
the true distribution due to aggregation. However, it ensures that key properties of the distribution that we are interested in are retained. In particular, because very few among the top $10 \%$ are net nominal borrowers, gross borrowing and lending are very close in the true and the approximating distributions. In addition, the approximating distributions retains asset positions conditional on age as well as conditional on wealth when net worth is split as top $10 \%$ and the rest, our key measures of concentration described.

\section{Asset endowments for a transiting individual household}

Consider the transition of an individual household's asset position from period $t-1$ into period $t$. We have treated both stocks and houses as long-lived trees and we normalize the number of trees carried into the period by consumers to one. We can thus measure the household's endowment of a long-lived asset from its share in total market capitalization of the asset in period $t-1$. The SCF does not contain consumption data. Using the language introduced in the discussion of the budget constraint (4), we can thus measure either initial or terminal wealth in a given period, but not both. We assume that terminal wealth can be directly taken from the survey. The initial supply of assets is normalized to one, so that the initial holdings of housing $\bar{\theta}_{t}^{h}$ and stocks $\bar{\theta}_{t}^{e}$ are the agent's market shares in period $t-1$. For each long-lived asset $a=h, e$, suppose that $w_{t-1}^{a}(i)$ is the market value of investor $i$ 's position in $t-1$ in asset $a$. Now we can measure household $i$ 's initial holdings as

$$
\begin{aligned}
\bar{\theta}_{t}^{a}(i) & =\theta_{t-1}^{a}(i)=\frac{w_{t-1}^{a}(i)}{i w_{t-1}^{a}(i)}=\frac{p_{t-1}^{a} \theta_{t-1}^{a}(i)}{p_{t-1}^{a} \theta_{t-1}^{a}(i)} \\
& =\text { market share of household } i \text { in period } t-1 .
\end{aligned}
$$

\section{Updating Nominal Positions}

For the nominal assets, the above approach does not work since these assets are short-term in our model. Instead, we determine the market value of nominal positions in period $t-1$ and update it to period $t$ by multiplying it with a nominal interest rate factor. In particular, suppose that $w_{t-1}^{b}(i)$ is the market value of investor $i$ 's net nominal positions in $t-1$ and that

$$
\begin{aligned}
\bar{\theta}_{t-1}^{b}(i) & =\frac{w_{t-1}^{b}(i)}{{ }_{i} w_{t-1}^{b}(i)} \\
& =\text { market share of household } i \text { in period } t-1
\end{aligned}
$$


We define the initial holdings of bonds for household $i$ as

$$
\begin{aligned}
\bar{b}_{t}(i) & =\left(1+i_{t-1}\right) \frac{w_{t-1}^{b}(i)}{\mathrm{GDP}_{t}} \\
& =\left(1+i_{t-1}\right) \frac{w_{t-1}^{b}(i)}{{ }_{i} w_{t-1}^{b}(i)} \frac{{ }_{i} w_{t-1}^{b}(i)}{\operatorname{GDP}_{t-1}} \frac{\operatorname{GDP}_{t-1}}{\mathrm{GDP}_{t}} .
\end{aligned}
$$

As an interest factor for a positive (lending) position, we use an average of 6-year bond rates between the 4 th year of period $t$ and the 4 th year of period $t-1$. We add a spread for the borrowing rate. The spread is $2 \%$ for 1995 and $2.75 \%$ for 1968 and 1978, for reasons described in the calibration section $\mathrm{V}$.

\section{Forecasting Income}

The final step in our construction of the joint income and endowment distribution is to specify the marginal distribution of non-asset income. Here we make use of the fact that income is observed in period $t-1$ in the SCF. We then assume that the transition between $t-1$ and $t$ is determined by a stochastic process for non-asset income. We employ the same process that agents in the model use to forecast their non-asset income, described in the next subsection. If the assumption were true, and if there were a large number of identical individuals in every cell, then our discretization implies that households in a cell should split up into nine different cells in the following period, with fractions provided by the probabilities of the income process. This is what we assume. As a result, the distribution of agents in period $t$ is approximated by $9 \times 6 \times 9=486$ different cells. For each cell, we know the endowment of assets as well as income, and we have a set of population weights that sums to the total population.

\section{Non-transiting households}

The previous discussion has covered only households who transit from period $t$ into period $t+1$. We also need to take into account the creation and destruction of households between $t-1$ and $t$. In years where successive SCFs are available, we calculate "birthrates" and "deathrates" for households directly by comparing these surveys. We assume that exiting households receive no labor income, but sell their assets and consume the proceeds, while entering households start with zero assets and the average labor income of their cohort. This is a simplified view that does not do justice to the many different reasons why households form and dissolve, and how wealth is passed along among 
households. However, we view it as a useful benchmark.

Time periods without two successive SCFs

For periods before 1980, the above strategy cannot be executed as is, because we do not have two consecutive SCFs. For the period 1965-70, the 1962 SCF is used to determine the initial endowment and income distribution. The only difficulty here is the adjustment of exiting and entering households. We use data from the Census Bureau on the evolution of household populations to gauge the size of exiters and entrants. The average labor income of the entering cohort is then estimated by multiplying per capita income of the young in the $1962 \mathrm{SCF}$ by the growth rate of aggregate per capita labor income.

For the period 1975-80, we do not have SCF information for period $t-1$. As for the 1960s, the updating of population weights is performed using Census data. To estimate the cross sectional distribution of endowments and income, we start from the 1962 distribution and its division of households into cells and modify cell holdings to obtain a new distribution. In particular, we calculate the unique distribution such that, for stocks, real estate, nominal assets, nominal debt and income, (i) aggregates match the aggregates from the FFA for the period 1969-74, (ii) the ratio of holdings between individual members of any two cells is the same as in the 1962 SCF and (iii) the relative size of a cell within its age cohort is the same as in the 1962 SCF.

Condition $(i)$ and $(i i)$ imply that per capita holdings or income within a cohort changes in order to account for differences in demographics while simultaneously matching aggregates. Conditions (ii) and (iii) imply that the cross section conditional on age is the same in the two years. The reason for using the 1962 distribution as the starting point rather than, say the 1989 distribution, is that the early 1970s aggregates - especially gross nominal assets - appear more similar to 1962 than to aggregates from the 1980s. Once we have a distribution of positions at the cell level for 1969-74, we proceed as above to generate an updated distribution for 1975-80.

\section{Asset Supply}

The endowment of the ROE sector consists of new equity issued during the trading period. The factor $f^{e}$ states this endowment relative to total market capitalization in the model. We thus use 
net new corporate equity divided by total household holdings of corporate equity. We obtain the corresponding measure for housing by dividing residential investment by the value of residential real estate. The calibration of the model uses six-year aggregates. The initial nominal position of the ROE is taken to be minus the aggregate (updated) net nominal position of the household sector. Finally, the new net nominal position of the ROE sector in period $t$ - in other words, the "supply of bonds" to the household sector - is taken to be minus the aggregate net nominal positions from the FFA for period $t$.

\section{B Baseline Expectations}

This appendix describes agents' expectations about returns and income in the future under the baseline scenario.

Non-Asset Income

We specify a stochastic process to describe consumer expectations about after-tax income. The functional form for this process is motivated by existing specifications for labor income that employ a deterministic trend to capture age-specific changes in income, as well as permanent and transitory components. In particular, following Zeldes (1989) and Gourinchas and Parker (2002), we assume that individual income $Y^{i}$ is

$$
Y_{t}^{i}=G_{t} A_{t} P_{t}^{i} U_{t}^{i}
$$

which has a common component $G_{t}$, an age profile $A_{t}$, a permanent idiosyncratic component $P_{t}^{i}$ and a transitory idiosyncratic component $U_{t}^{i}$.

The growth rate of the common component $G_{t}$ is equal to the growth rate of aggregates, such as GDP and aggregate income, in the economy. It is common to specify the transitory idiosyncratic component as lognormally distributed

$$
\ln U_{t}^{i}=N\left(-\frac{1}{2} \sigma_{u}^{2}, \sigma_{u}^{2}\right)
$$

so that $U_{t}^{i}$ is i.i.d with mean one. The permanent component $P_{t}^{i}$ follows a random walk with mean one. The permanent component solves

$$
\ln P_{t}^{i}=\ln P_{t-1}^{i}+\varepsilon_{t}^{i}-\frac{1}{2} \sigma_{\varepsilon}^{2}
$$


where $\varepsilon_{t}^{i}$ are normal shocks with zero mean and standard deviation $\sigma\left(\varepsilon_{t}^{i}\right)$. In our numerical procedures, we discretize the state process using Gauss-Hermite quadrature with three states.

We estimate the age profile $G_{t}$ as average income in each age-cohort from the SCF:

$$
\frac{1}{\# a} \sum_{i \in a} Y_{t}^{i}=A_{t} G_{t} \frac{1}{\# a} \sum_{i \in a} P_{t}^{i}
$$

with $\operatorname{plim} \frac{1}{\# a} \sum_{i \in a} P_{t}^{i}=1$. Table B.1 reports the profile relative to the income of the youngest cohort.

Table B.1: Income Age profile

\begin{tabular}{cccccccccc}
29 & 35 & 41 & 47 & 53 & 59 & 65 & 71 & 77 & $88+$ \\
\hline 2.04 & 2.51 & 3.17 & 3.80 & 4.56 & 3.81 & 3.00 & 1.93 & 1.42 & 1.17
\end{tabular}

Note: Income age profiles estimated from the SCF. The numbers represent the average cohort income relative to the average income of the youngest cohort ( $\leq 23$ years).

We obtain an estimate of the variance of permanent shocks by computing the cross-sectional variance of labor income for each cohort before retirement ( $<65$ years) and then regressing it on a constant and cohort age. The intercept of this regression line is .78, while the annualized slope coefficient is .014. ${ }^{11}$ We thus set $\sigma_{\varepsilon}^{2}=1.4 \%$ and time-aggregate this variance for our six-year periods. This number is in line with more sophisticated estimations of labor income processes, which tend to produce estimates between $1 \%$ and $2 \%$ per year.

Typical estimates of the variance of temporary shocks $\sigma_{u}^{2}$ are 2-10 times larger than those of the variance of permanent shocks. Moreover, several studies have shown that the variance of temporary shocks to log wages has increased since the 1970s. For example, Heathcote et al. (2004) show that the variance of $\log$ wages increased from about .05 in the 1970s to .07 in 1995 . To capture this increase in temporary income risk, we adopt their numbers, thus assuming that the variance of hours is constant. We set $\sigma_{u}^{2}=.05$ for the years 1968 and 1978 and $\sigma_{u}^{2}=.07$ for $1995 .{ }^{12}$ In all years, agents in the model assume that this variance is fixed forever. Finally, we determine the variance of

\footnotetext{
${ }^{11}$ Of course, this simple approach uses only the cross-section and thus potentially confounds age and time or cohort effects. However, when we rerun the regression with SCF wages, using the similar sample selection criteria as Storesletten et al. (2004), our results are close to what these authors find for 1995 from an analysis with panel data on wages.

${ }^{12}$ The fixed effects only matter for the updating of the income distribution, as explained in the previous section. The model's results are not sensitive to the magnitude of these effects. For example, the results based on our model are unchanged when we use the estimates provided by Heathcote et al. (2004).
} 
the first draw of permanent income from the intercept of our regression line. For the earlier years, we scale down this initial variance by the relative change in the permanent component of income for the youngest agents in Heathcote et al. (2004). This is a simple way to accommodate changes in income due to education over time. Sensitivity checks have shown that the initial draw of permanent income does not matter much for the results, since it does not directly affect the portfolio problem.

Most labor income studies focus on pre-retirement income. There are major challenges to obtaining variance estimates for retirement income. For example, older households tend to experience large shocks to health expenditures, which are included as NIPA income if they are disbursed by health plans. These shocks contain both transitory and permanent components (see the estimates reported in Appendix A, Hubbard, Skinner, and Zeldes 1994). Since these shocks are hard to measure at the household level, we could try to ignore their variances and assume that household receive a safe stream of income during retirement. However, this implies that precautionary savings drop dramatically as soon as the household enters retirement in the absence of such shocks. This prediction is not consistent with the household savings data from the SCF. For this reason, we apply the above shocks to income at any age, including retirement.

\section{Returns and aggregate growth}

We assume that consumers believe real asset returns and aggregate growth to be serially independent over successive six year periods. Moreover, when computing an equilibrium for a given period $t$, we assume that returns are identically distributed for periods beyond $t+1$. We will refer to this set of beliefs - to be described below - as baseline beliefs. However, in our exercises we will allow beliefs for returns between $t$ and $t+1$ to differ. For example, we will explore what happens when expected inflation is higher over the next six year period. We discuss the latter aspect of beliefs below when we present our results. Here we focus on how we fix the baseline.

To pick numbers for baseline beliefs, we start from empirical moments. Table B.2 reports summary statistics on ex-post realized pre-tax real returns on fixed income securities, residential real estate and equity, as well as inflation and growth. These returns are measured over six year periods, but reported at annualized rates. Since we work with aggregate portfolio data from the FFA, we construct returns on corporate equity and residential real estate directly from FFA aggregates. 
Table B.2: Summary Statistics

\begin{tabular}{rrrrr}
$r_{t}^{b}$ & $r_{t}^{h}$ & \multicolumn{1}{c}{$r_{t}^{e}$} & \multicolumn{1}{c}{$\pi_{t}$} & \multicolumn{1}{c}{$g_{t}$} \\
\hline \multicolumn{5}{c}{ Means } \\
2.68 & 4.81 & 8.51 & 4.01 & 2.19 \\
Standard & Deviations / Correlations \\
3.24 & -0.02 & 0.56 & -0.04 & 0.33 \\
-0.02 & 3.31 & -0.04 & -0.13 & 0.38 \\
0.56 & -0.04 & 22.87 & -0.52 & 0.20 \\
-0.04 & -0.13 & -0.52 & 5.60 & -0.40 \\
0.33 & 0.38 & 0.20 & -0.40 & 1.31 \\
\multicolumn{5}{c}{ Sharpe Ratios } \\
0.45 & 0.27 &
\end{tabular}

NoтE: The table reports annualized summary statistics of six-year log real returns. Below the means, the matrix has standard deviations on the diagonal and correlations on the offdiagonal. The last row contains the Sharpe ratios. The log inflation rate $\pi_{t}$ is computed using the CPI, while $g_{t}$ is the log growth rate of GDP multiplied by the factor $2.2 / 3.3$ to match the mean growth rate of consumption.

Baseline beliefs assume that the payoff on bonds $1 / \pi_{t+1}$ is based on a (net) inflation rate $\pi_{t+1}-1$ with a mean of $4 \%$ per year, and that the volatility of $\pi_{t+1}$ is the same as the unconditional volatility of real bond returns, about $1.3 \%$ per year. To obtain capital gains from period $t$ to $t+1$, we take the value of total outstandings from the FFA in $t+1$, and subtract the value of net new issues (or, in the case of real estate, new construction.) To obtain dividends on equity in period $t$, we use aggregate net dividends. To obtain dividends on real estate, we take total residential housing sector output from the NIPA, and subtract materials used by the housing sector. For bond returns, we use a six year nominal interest rate derived by extrapolation from the term structure in CRSP, and subtract realized inflation, measured by the CPI. Here growth is real GDP growth.

The properties of the equity and bond returns are relatively standard. The return on bonds has a low mean of $2.7 \%$ and a low standard deviation of $3.2 \%$. The return on stocks has a high mean of $8.5 \%$ and a standard deviation of $23 \%$. What is less familiar is the aggregate return on residential real estate: it has a mean and standard deviation in between the other two assets. It is apparent that the Sharpe ratio of aggregate housing is much higher than that on stocks.

In principle, we could use the numbers from Table B.2 directly for our benchmark beliefs. However, this would not capture the tradeoff faced by the typical individual household. Indeed, the 
housing returns in Table B.2 are for the aggregate housing stock, while real estate is typically a non-diversified investment. It is implausible to assume that investors were able to pick a portfolio of real estate with return characteristics as in Table B.2 at any time over our sample period. Instead, the typical investor picks real estate by selecting a few properties local markets.

Existing evidence suggests that the volatility of house returns at the metro area, and even at the neighborhood or property level are significantly higher than returns at the national aggregate. For example, Caplin et al. (1997) argue that $1 / 4$ of the overall volatility is aggregate, $1 / 4$ is citycomponent, and 1/2 is idiosyncratic. Tables $1 \mathrm{~A}$ and $1 \mathrm{~B}$ in Flavin and Yamashita (2002) together with Appendix C in Piazzesi, Schneider, and Tuzel (2007) confirm this decomposition of housing returns. As a simple way to capture this higher property-level volatility, we add idiosyncratic shocks to the variance of housing returns that have volatility equal to 3.5 times aggregate volatility. ${ }^{13}$ Finally, we assume that expected future real rents are constant. This ignores the volatility of real rent growth, which is small, at around $2 \%$ per year.

\section{Taxes on investment}

Investors care about after-tax real returns. In particular, taxes affect the relative attractiveness of equity and real estate. On the one hand, dividends on owner-occupied housing are directly consumed and hence not taxed, while dividends on stocks are subject to income tax. On the other hand, capital gains on housing are more easily sheltered from taxes than capital gains on stocks. This is because many consumers simply live in their house for a long period of time and never realize the capital gains. Capital gains tax matters especially in inflationary times, because the nominal gain is taxed: the effective real after tax return on an asset subject to capital gains tax is therefore lower when inflation occurs.

To measure the effect of capital gains taxes, one would ideally like to explicitly distinguish realized and unrealized capital gains. However, this would involve introducing state variables to keep track of past individual asset purchase decisions. To keep the problem manageable, we adopt a simpler approach: we adjust our benchmark returns to capture the effects described above. For our baseline set of results, we assume proportional taxes, and we set both the capital gains tax rate and the

\footnotetext{
${ }^{13}$ Since the volatility of housing is measured imprecisely, we chose the precise number for the multiplicative factor such that the aggregate share of housing in the model roughly matches the FFA data. The resulting factor is 3.5 , close to the rule-of-thumb factor of 4 .
} 
income tax rate to $20 \%$. We define after tax real stock returns by subtracting $20 \%$ from realized net real stock returns and then further subtracting $20 \%$ times the realized rate of inflation to capture the fact that nominal capital gains are taxed. In contrast, we assume that returns on real estate are not taxed. 